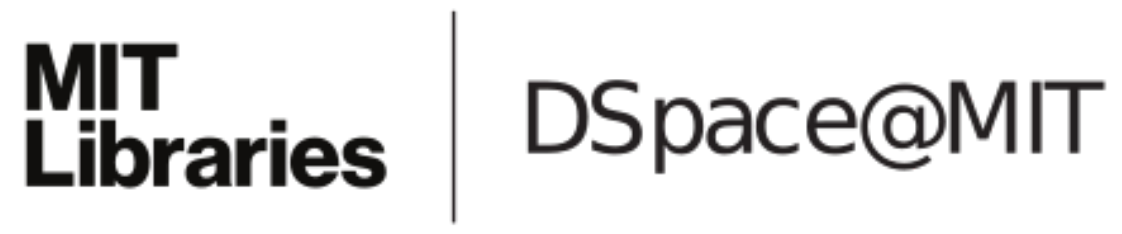

\author{
MIT Open Access Articles
}

Corrective but coordinates clauses not always but sometimes

The MIT Faculty has made this article openly available. Please share how this access benefits you. Your story matters.

Citation: Toosarvandani, Maziar. "Corrective but Coordinates Clauses Not Always but Sometimes." Nat Lang Linguist Theory 31, no. 3 (June 25, 2013): 827-863.

As Published: http://dx.doi.org/10.1007/s11049-013-9198-4

Publisher: Springer Netherlands

Persistent URL: http://hdl.handle.net/1721.1/103362

Version: Author's final manuscript: final author's manuscript post peer review, without publisher's formatting or copy editing

Terms of Use: Article is made available in accordance with the publisher's policy and may be subject to US copyright law. Please refer to the publisher's site for terms of use. 


\title{
Corrective but coordinates clauses not always but sometimes
}

\author{
Maziar Toosarvandani \\ Massachusetts Institute of Technology
}

Received: 19 August 2010 / Accepted: 17 April 2012

\begin{abstract}
The semantic contrast between COUNTEREXPECTATIONAL and CORRECTIVE but has long interested linguists (see Anscombre and Ducrot 1977 and much subsequent work). Recently, Vicente (2010) has proposed that the two types of but also differ in their syntax. While counterexpectational but coordinates constituents from a variety of different categories, corrective but always coordinates full clauses. These clausal coordination structures are then subject to reduction by ellipsis to derive their surface form. I argue that this CLAUSE-ONLY COORDINATION HYPOTHESIS is incorrect. Corrective but, like other coordinators, is able to combine both clausal and subclausal constituents. Only a crosscategorial syntax for corrective but accounts for the full range of contexts in which it occurs. Furthermore, when ellipsis does apply, it often must apply to subclausal coordination structures for its identity constraint to be satisfied.
\end{abstract}

Keywords: coordination, negation, ellipsis, gapping

\section{Introduction}

Since at least the work of Anscombre and Ducrot (1977), linguists have observed that the coordinator but has two seemingly distinct meanings. (Other early discussions include Lang 1984:238-262 and Horn 2001:402-413.) On the one hand, there is the well-known COUNTEREXPECTATIONAL meaning of but, illustrated in (1), and, on the other hand, there is its CORRECTIVE meaning, illustrated in (2). ${ }^{1}$

(1) Max eats chard but hates it.

counterexpectational

(2) Max doesn't eat chard, but spinach.

corrective

Both types of but have truth conditions identical to those of and. The counterexpectational sentence in (1) is true just in case Max eats chard and he hates it, as shown by the translation in (3); and, the corrective sentence in (2) is true just in case Max does not eat chard and he eats spinach,

\footnotetext{
${ }^{1}$ The term 'corrective' is a misnomer, since this but does not actually require the speaker to correct a previous utterance, though this is a possible use (McCawley 1991; Toosarvandani 2010:49-50, to appear, pp. 26-30).
} 
as shown by the translation in (4). Counterexpectational but, however, contributes another meaning component. It conventionally implicates that generally, if the first conjunct holds, the second conjunct does not. So, in (1), we are led to expect that, if Max eats chard, he is not going to hate it. This implicature is explicitly denied by the second conjunct itself-Max eats chard, and he DOES hate it. ${ }^{2}$ No such expectation is present in the corrective but sentence in (2).

$$
\begin{aligned}
\llbracket(1) \rrbracket= & \operatorname{eat}(\operatorname{chard})(\max ) \wedge \text { hate }(\operatorname{chard})(\max ) \\
& \text { Expectation: eat }(\operatorname{chard})(\max ) \rightarrow \neg \text { hate }(\operatorname{chard})(\max ) \\
\llbracket(2) \rrbracket= & \neg \operatorname{eat}(\operatorname{chard})(\max ) \wedge \operatorname{eat}(\operatorname{spinach})(\max )
\end{aligned}
$$

Since, in such diverse languages as German (Pusch 1975; Abraham 1979; Lang 1984:238-262), Hebrew (Dascal and Katriel 1977), Persian (Toosarvandani 2010:26f.), and Spanish (Schwenter 2000; Vicente 2010) the counterexpectational and corrective meanings are associated with phonologically distinct lexical items, it is usually assumed that English, too, has two distinct lexical items, though they are both pronounced as but. ${ }^{3}$

In a recent paper, Vicente (2010) proposes that counterexpectational and corrective but differ not just in their semantics but also in their syntax. Both are coordinators, which usually combine constituents from a variety of different types (Huddleston and Pullum 2002:1291). But while counterexpectational but has the typical crosscategorial syntax of a coordinator, corrective but only combines full clauses. These claims about the syntax of but can be summarized as follows:

(5) a. Corrective but (sino) always requires its conjuncts to be full clauses.

b. Counterexpectational but (pero) allows its conjuncts to be smaller than clauses.

(Vicente 2010:385)

I do not dispute that counterexpectational but coordinates constituents of any size. I take up instead Vicente's conjecture that corrective but in English only coordinates full clauses - (5a) abovewhich for convenience I will call the CLAUSE-ONLY COORDINATION HYPOTHESIS. I will not be concerned with the syntax of either sino or pero, which are the lexical items in Spanish dedicated to the corrective and counterexpectational uses of but, respectively.

At first glance, the Clause-Only Coordination Hypothesis would seem to fail immediately to account for examples like (2), where the constituent following corrective but is not a full clause but the DP spinach. How does corrective but always coordinate full clauses if, on the surface, it can be followed by just a subclausal constituent? Paralleling earlier work by McCawley (1991, 1998:612-622), Vicente argues - convincingly, I think - that corrective but sometimes coordinates constituents somewhat larger than what is visible on the surface because ellipsis applies to reduce the second coordinate to a remnant. In (2), for instance, he assumes that corrective but coordinates two full clauses, though everything in the second one is not pronounced (represented by striking it out), except for the DP spinach:

[[Max doesn't eat chard] but [Max eats spinach]].

\footnotetext{
${ }^{2}$ Because the expectational component can be denied, it is usually treated, following Grice (1975), as a conventional implicature — though, see Bach 1999 for a dissenting view.

${ }^{3}$ In Toosarvandani (to appear), I argue that English but is, in fact, polysemous in the same way that modals are, and that this gives rise to its counterexpectational and corrective uses.
} 
Vicente's account of (2) in terms of clausal coordination followed by ellipsis makes sense of the interpretation of this sentence. As shown by the translation in (4), sentence negation, which occurs at the left edge of the verb phrase, is interpreted inside the first conjunct. Corrective but therefore coordinates constituents large enough to contain sentence negation in the first coordinate, even though all we see is a DP following corrective but.

While (2) may not be so problematic, the Clause-Only Coordination Hypothesis nevertheless cannot be maintained. I argue that corrective but is able, like other coordinators, to combine constituents from a wide variety of types, and that sometimes these are constituents smaller than a full clause:

$$
\begin{aligned}
& \text { Max eats not chard but spinach. } \\
& \llbracket(7) \rrbracket=\neg \operatorname{eat}(\operatorname{chard})(\max ) \wedge \operatorname{eat}(\operatorname{spinach})(\max )
\end{aligned}
$$

The sentence in (2) and the one in (7) have the same meaning. Comparing the logical translations in (4) and (8), they both entail that Max does NOT eat chard and that he DOES eat spinach. There is a negative element in corrective but's first conjunct-sentence negation in (2) and constituent negation in (7). This negative element is obligatory, since removing it from either sentence is infelicitous, e.g. \#Max eats chard but spinach. I show that, in examples like (7), corrective but coordinates two subclausal constituents - in this case, two DPs - contra the Clause-Only Coordination Hypothesis.

This is a positive result because there is something suspiciously arbitrary about the ClauseOnly Coordination Hypothesis. Why would corrective but combine full clauses and not some other category - say, noun phrases or verb phrases? After all, a coordinator like and is able to have a crosscategorial distribution because of its meaning. As Keenan and Faltz (1985:46) put it, "the meaning of and is much more general and much more abstract, for it relates meanings drawn from essentially ANY type. Its meaning is category independent, since no matter what type is chosen, and relates pairs of meanings from that type in the same way, namely, in the way expressed by the meet operator in boolean algebra..." Since the coordinator and expresses a relation between the elements in a category that does not depend on what that category is or any particular properties its elements may have, it can combine members from a wide variety of categories. Corrective but has precisely the same meaning as and, so a restriction on the syntactic categories it can coordinate, such as the Clause-Only Coordination Hypothesis, would be entirely unmotivated from the perspective of its meaning.

My argument proceeds in the following way. First, in Section 2, I present an array of corrective but sentences like (7), which I argue involve subclausal coordination without any ellipsis. Then, in Section 3, I defuse three syntactic arguments against a subclausal coordination analysis for these sentences, involving agreement, binding, and the Coordinate Structure Constraint. In Section 4, I consider a semantic argument against the subclausal coordination analysis - involving the interpretation of negation - and show that it is not really an argument at all. In Section 5, I turn to the reduction operation that is active in corrective but sentences, showing that its interaction with coordination is more complicated than originally thought. While ellipsis can apply to clausal coordination structures with corrective but, it can also apply to subclausal coordination structures, including some of the original corrective but sentences that Vicente was interested in. In a sentence like (2), ellipsis must, in fact, apply to the coordination of vPs for its identity constraint to be satisfied. Finally, in Section 6, I close by raising some open questions this more elaborate understanding 
of the syntax of corrective but raises for the theory of ellipsis in coordination structures.

\section{Two forms of corrective but}

Consider the two corrective but sentences from above side by side. Both have the same meaning. Neither (9) nor (10) has an expectation that is denied. Both sentences are true just in case Max does not eat chard and he does eat spinach.

(9) Max doesn't eat chard, but spinach.

anchored form

Max eats not chard but spinach.

basic form

McCawley (1991) calls sentences like (9) with sentence negation corrective but's ANCHORED FORM; and, he calls sentences like (10) with constituent negation its BASIC FORM. This is a useful terminological distinction - and I will use it for now - but it will not translate ultimately into a useful analytical distinction.

Why are there different negative elements in the anchored and basic forms? To answer this question, I start with why corrective but's first coordinate always contains a negative element. In work elsewhere (Toosarvandani, to appear), I argue that corrective but imposes a pragmatic constraint on the question under discussion. The first conjunct of a corrective but sentence must entail, and the second conjunct must entail the negation of, different answers to the same, sometimes unpronounced, negative wh-question. This constraint is satisfied if the first coordinate contains a negative element and the second coordinate does not. ${ }^{4} \mathrm{I}$ am being careful to talk about a 'negative element' since, as we will see in Section 2.3, this does not always have to be negation.

I follow Vicente in taking the anchored form to involve coordination of relatively large constituents - large enough to contain sentence negation in its first coordinate - the second coordinate of which ellipsis reduces to a remnant. In the basic form, though, I propose that corrective but coordinates two subclausal constituents. If, in (10), corrective but conjoins two DPs, as shown in (11), no ellipsis is necessary to derive the surface string. (I stick here with a tribranching structure for coordination out of convenience; nothing I say here rules out an asymmetric structure like Munn's (1993).)

${ }^{4}$ As Horn (2001:392) observes, corrective but is not licensed by incorporated negation:

$$
\text { Einstein's approach was }\left\{\begin{array}{c}
\text { not religious } \\
\text { \#irreligious }
\end{array}\right\} \text {, but rational. }
$$

A reviewer takes contrasts like (i) to show that corrective but's need for a negative element is morphosyntactic in nature rather than pragmatic. Kasimir suggests that incorporated negation is infelicitous with corrective but because, unlike sentence negation, it does not obey the Law of the Excluded Middle $(p \vee \neg p)$. There are, however, adjectives with incorporated negation that do obey the Law of the Excluded Middle (e.g. impossible). In Toosarvandani (to appear), I propose that corrective but sentences answer sometimes implicit negative wh-questions, and that a sentence with incorporated negation cannot serve as a felicitous answer to a negative wh-question. 
(11)

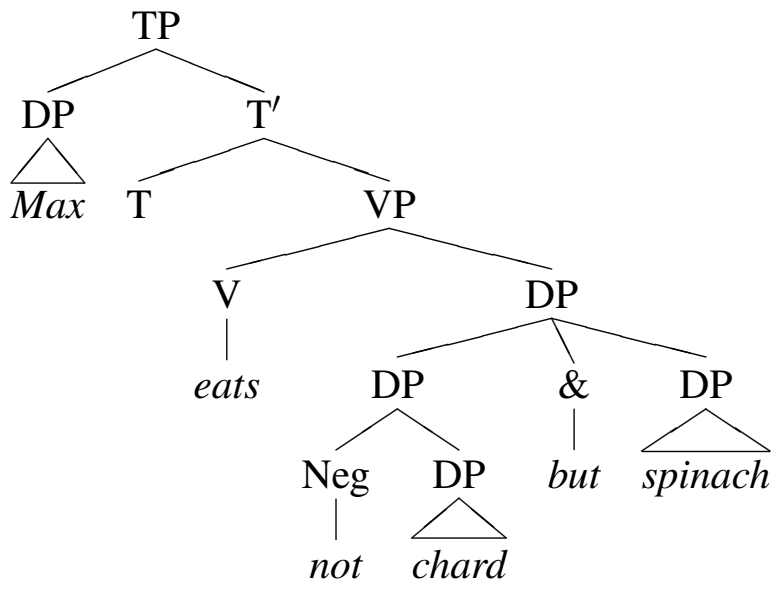

With corrective but coordinating DPs, the negative element in the first coordinate cannot be sentence negation, which occurs at the left edge of the verb phrase. Instead, the negative element in this basic form sentence is constituent negation, which adjoins to the first DP coordinate (cf. Iatridou 1990:574; Kim and Sag 2002:351-364).

As expected, corrective but exhibits all the properties of a coordinator in the basic form. It combines two constituents of the same type, such that the resulting coordinate structure has a distribution identical to the original constituents. And, these subclausal coordination structures behave like a single constituent. They can be fronted (12), and they can appear in the pivot of an it-cleft (13) or a pseudocleft (14).

(12) Content with Hermia! No; I do repent / The tedious minutes I with her have spent. / Not Hermia but Helena now I love. ${ }^{5}$

(13) The Queen of Hearts is no longer making idle threats and when her minions are after Alice, it's not wordplay but weaponplay that's needed. ${ }^{6}$

(14) What is the evidence which impels Mr. Ellmann to defend 'Wilde's subtle effort' against Proust? As far as I know, what Wilde's bon mot aroused was not Proust's indignation but his compassion. ${ }^{7}$

A central property of prototypical coordinators like and or or is that they are able to combine constituents from a wide variety of types (Huddleston and Pullum 2002:1291). Corrective but coordinates various subclausal constituents, with constituent negation adjoining to the first coordinate:

Not the neighborhood library perhaps, but the special engineering library will play a crucial role. ${ }^{8}$

But the putting-forward, not of detailed and scientifically 'finished' hypotheses, but of schemata for hypotheses, has long been a function of philosophy. ${ }^{9}$

\footnotetext{
${ }^{5}$ William Shakespeare. A midsummer night's dream, Act II, Scene 2, lines 111-113.

${ }^{6} \mathrm{http} / / / \mathrm{www} . c h a l l e n g i n g d e s t i n y . c o m / r e v i e w s / a l i c e . h t m$, March 24, 2009.

${ }^{7}$ Susan Sontag. 'Vautrin's cigar.' The New York Review of Books. October 27, 1977. Accessed from http://www. nybooks.com/articles/8365.

${ }^{8} \mathrm{http}: / /$ www.kurzweilai.net/may-the-smartest-machine-win-warfare-in-the-21st-century, March 19, 2011.

${ }^{9}$ Hilary Putnam. 1975. Mind, language, and reality: Philosophical papers, Volume 2. Cambridge: Cambridge University Press, p. 433.
} 
(17) Not one but two former home secretaries have blamed television and films for what is happening in society. ${ }^{10}$

(18) What was true, however, was that the I.O. was bound not to but from Guernsey, where she had loaded a goodly cargo of brandy and gin...11

(19) The tragedy of The Changeling is an eternal tragedy, as permanent as CEdipus or Antony and Cleopatra; it is the tragedy of the not naturally bad but irresponsible and undeveloped nature, caught in the consequences of its own action. ${ }^{12}$

(20) We were shown how we were being not slowly but quickly poisoned and we demanded and obtained a pure food law. ${ }^{13}$

These basic form sentences all have parses available where corrective but coordinates subclausal constituents with no ellipsis: i.e. DPs (15), PPs (16), determiners (17), prepositions (18), and nominal or verbal modifiers (19-20). ${ }^{14}$

I am proposing that the basic form sentences in (10-20) all involve subclausal coordinationthereby falsifying the Clause-Only Coordination Hypothesis - and that no ellipsis applies to derive their surface form. Of course, coordinate structures are often structurally ambiguous, since various operations can obscure their underlying form. Therefore, I still need to show that subclaual coordination with no ellipsis is the ONLY possible parse for these sentences. Below, I consider three possible alternatives. The first two alternatives treat basic form sentences as underlying clausal coordination structures to which either ellipsis applies, as in Section 2.1, or movement, as in Section 2.2. The final alternative, which I discuss in Section 2.3, treats corrective but in the basic form as an entirely different lexical item, saving the Clause-Only Coordination Hypothesis, but only by removing the offending sentences from its purview. None of these alternatives can account for the full range of corrective but sentences that is attested.

\subsection{The basic form does not involve ellipsis}

Suppose that, in basic form sentences, corrective but did indeed coordinate full clauses. How, then, would their surface forms, in which only a single full clause is evident, arise? McCawley

\footnotetext{
${ }^{10}$ The British National Corpus, K5C 880.

${ }^{11}$ E. Keble Chatterton. 1912. King's cutters and smugglers, 1700-1855. London: George Allen and Company, p. 205.

${ }^{12}$ Frank Kermode, ed. 1975. Selected prose of T. S. Eliot. New York: Mariner Books, p. 190.

${ }^{13}$ Julian Heath. 1913. Work of the Housewives League. The Annals of the American Academy of Political and Social Science 48:121-126.

${ }^{14}$ Corrective but can also coordinate nonfinite and finite embedded clauses, as in (i) and (ii) respectively.
}

(i) The attempt not to impose meaning on the students, but to allow meaning to be discovered intersubjectively, was fairly successful when reading Lord of the Flies and Animal Farm in the ways described above. (Roger Elliott. 1990. Encouraging reader-response to literature in ESL situations. ELT Journal 44:191-198.)

(ii) But even if we accept the branching idea — not that humans descended directly from the ape but that both share a common ancestor - a formidable stumbling block remained.

(Friedel Weinert. 2009. Copernicus, Darwin, \& Freud: Revolution in the history and philosophy of science. Oxford: Wiley-Blackwell, p. 132.)

These obviously do not bear on the question of whether the Clause-Only Coordination Hypothesis holds or not. 
(1991:198f.) proposes that, just like the anchored form, the basic form involves clausal coordination and ellipsis. The sentence in (10), for instance, would have a structure roughly like the following:

[[Max eats not chard] but [Max eats spinach $]]$.

Just like the anchored form sentence in (9), everything in the second conjunct would be deleted except for the DP spinach. If such an analysis were available for all basic form sentences, the Clause-Only Coordination Hypothesis could be maintained. There are three arguments, however, that it is not, in fact, available. ${ }^{15}$

\subsubsection{Argument 1: The basic form does not obey islands}

In the anchored form, the remnant cannot originate inside an island, as Vicente (2010:394-398) shows for the Coordinate Structure Constraint (22a) and for adjunct islands (22d). To these, I add the sentential subject constraint (22b) and the Complex NP Constraint (22c).

$$
\begin{aligned}
& \text { a. * Alfonse didn't cook rice and beans, but potatoes. }(=\ldots \text { but Alfonse cooked [rice } \\
& \text { and potatoes].) }
\end{aligned}
$$

\footnotetext{
${ }^{15}$ There is another way in which the constituent following corrective but in the basic form does not behave like the remnant in the anchored form. As Vicente demonstrates for Spanish (p. 398f.) — a language with obligatory piedpiping of prepositions - the preposition in the remnant cannot be omitted. When sino, the correlate of corrective but, occurs in the anchored form with sentence negation (no), a preposition in the remnant, such as con 'with' in (i), cannot be omitted without resulting in ungrammaticality, as in (ii).
}

(i) No he visto a una chica con un vestido azul sino con zapatos negros. not have seen to a girl with a dress blue but with shoes black

'I haven't seen a girl in a blue dress, but a girl in black shoes.'

(ii) $?^{*}$ No he visto a una chica con un vestido azul sino zapatos negros. not have seen to a girl with a dress blue but shoes black

'I haven't seen a girl in a blue dress, but a girl in black shoes.' (Vicente 2010:398)

For Vicente, this is because the remnant in the anchored form undergoes movement, as I will discuss in detail in Section 5.

In the text, I am concerned with corrective but in English, but we can test whether sino in Spanish also allows preposition stranding in the basic form. When it appears with constituent negation in its first coordinate, the following phrase need not include the preposition:

(iii) En este caso participar tiene que ver con no sólo aportar recursos, sino in this case participate.INFIN have.PRES.3SG that see.INFIN with not only contribute.INFIN resources but decidir acerca de su uso. decide.INFIN about of its use

'In this case, participating has to do not only with the contributing resources, but deciding about their use.' (http://www.monografias.com/trabajos31/notas-escuela-comunidad/notas-escuela-comunidad.shtml, December 8, 2011)

In (iii), a DP, decidir acerca de su uso 'deciding about their use', follows sino. If this constituent were the remnant of the same ellipsis operation found in the anchored form, this would be completely unexpected. But if, as I am arguing, corrective but can coordinate subclausal constituents, (iii) would simply involve a DP coordination structure embedded under the preposition con 'with'. The basic form thus appears to permit preposition stranding because it does not involve ellipsis. 
b. * That Alfonse ate the rice isn't fantastic, but the beans. $(=\ldots$ but [that Alfonse ate the beans] is fantastic.)

c. * Alfonse didn't smash the vase that Sonya had brought from China, but from Japan. (= ...but Alfonse smashed [the vase that Sonya had brought from Japan].)

d. * Jasper didn't choke when he saw Sally, but John. (= . . but Jasper choked [when he saw John].)

These sentences are all ungrammatical because the constituent following corrective but originates inside an island. Since the island itself goes missing, the judgments are given relative to a certain interpretation. The sentence in (22a), for instance, is ungrammatical under an interpretation in which Alfonse cooks both rice and potatoes.

The parallel basic form sentences do not show the same island sensitivity:
a. Alfonse cooked rice and not beans but potatoes.
b. That Alfonse ate not the rice but the beans is fantastic.
c. Alfonse smashed the vase that Sonya had brought not from China but from Japan.
d. Jasper choked when he saw not Sally but John.

The sentences in (23a-d) are all grammatical with the relevant interpretations. For example, (23a) entails that Alfonse cooked both rice and potatoes. I conclude that this 'island-containing' interpretation arises because, in these basic form sentences, corrective but simply coordinates subclausal constituents, and consequently there is no island present to induce an island violation. In (23a), the DP potatoes is simply coordinated with the DP not beans by corrective but, and this coordinate structure is coordinated with rice by and.

As a reviewer observes, a proponent of the Clause-Only Coordination Hypothesis could assume that, as in the anchored form, corrective but in the basic form coordinates clauses, but that the type of ellipsis active in the basic form violates island constraints. There are, after all, some types of ellipsis where the remnant exhibits island-violating behavior. As was famously observed by Ross (1969:276f.), the wh-phrase remnant in sluicing can originate inside an island when it has an overt indefinite correlate. Consider, for instance, (24), where the indefinite correlate some language of the wh-remnant which language is contained within a complex NP island.

(24) The administration has issued a statement that it is willing to meet with one of the student groups, but I'm not sure which.

(Chung et al. 1995:272)

(25) * Tony sent Mo a picture that he painted, but it's not clear with what.

(Chung et al. 1995:279)

* Abby wants to hire someone who speaks GREEK, but I don't remember what OTHER languages.

(Merchant 2008:148)

Crucially, however, when the remnant lacks an overt correlate altogether, as in (25), it does obey island constraints (Chung et al. 1995:278f.). Or, when, as in (26), the remnant (what other languages) stands in a contrastive focus relationship to its correlate (Greek), it also obeys islands (Merchant 2008:148).

This last case is particularly relevant since the remnant in anchored form sentences is in the same contrastive focus relationship to its correlate in the first conjunct, as shown in (27). It seems 
plausible to assume that the island sensitivity of corrective but's remnant should have the same source as that of contrast sluices like (26), which Merchant (2008:150f.) attributes to the islandsensitive nature of covert focus movement.

$$
\text { Max does not eat CHARD, but SPINACH. }
$$

$$
\text { Max eats not CHARD but SPINACH. }
$$

But as shown in (28), the corresponding basic form sentence has an identical focus structure. Consequently, if the constituent following corrective but were, indeed, the remnant of ellipsis, it would be highly mysterious why it would not also be sensitive to island constraints. The partisan of the Clause-Only Coordinate Hypothesis would somehow have to tie the island (in)sensitivity of the constituent following corrective but to the choice between sentence and constituent negation. Without such a connection - which, to my mind, is not at all obvious - positing an island-insensitive ellipsis operation solely for the basic form strikes me as ad hoc. In contrast, if corrective but coordinates subclausal constituents in the basic form, as I am arguing, then its island insensitivity would fall out without any additional assumptions.

\subsubsection{Argument 2: The surface string for all basic form sentences cannot be generated by clausal coordination}

There are basic form sentences whose surface strings are impossible to generate through ellipsis applied to clausal coordination structures. In the anchored form, corrective but and the accompanying remnant always occur in sentence-final position. Since the second coordinate follows the first coordinate, the remnant, which derives from the second coordinate, always occurs after all material in the first coordinate. In the basic form, however, corrective but need not occur in sentence-final position. As Vicente (2010:400) observes, it can occur in sentence-initial position (see also (15) and (17) above):

a. Not a mathematician but a physicist discovered the neutron.

b. Not three but four girls are sunbathing on the lawn.

(Vicente 2010:400)

Ellipsis cannot derive the sentences in (29) since this would require it to apply to the first coordinate. That is, their structures would have to be:

(30) a. [[Not a mathematician discovered the neutron] but [a physicist discovered the neutron]].

b. [[Not three girls are sunbathing on the lawn] but [four girls are sunbathing on the lawn]].

But as Vicente (2010:388) mentions, the Backwards Anaphora Constraint prevents ellipsis from applying to an element that precedes its antecedent in a coordinate structure (Langacker 1969:171). A structure like (30a) or (30b) is thus impossible for basic form sentences where corrective but occurs in initial position.

Early generative work did countenance an operation of backwards gapping, particularly in verb-final languages like Japanese (Ross 1970). Hankamer (1979:103-123) shows, however, that these gaps actually involve a different operation - right node raising — which is standardly analyzed as rightward across-the-board movement (see Sabbagh 2007 for a recent discussion). Right 
node raising cannot be responsible for deriving the basic form sentence in (29a) for two reasons. First, right node raising has a distinctive intonational contour, which Selkirk (2002) describes as the DUNCECAP pattern (see also Hartmann 2001:88-108). In a typical right-node-raising sentence, the right edge of each TP coordinate bears a $\mathrm{L}+\mathrm{H}^{*} \mathrm{~L}-$ contour - that is, a sharp rise to a high pitch accent on the last stressed syllable $\left(\mathrm{L}+\mathrm{H}^{*}\right)$ followed by a sharp fall $(\mathrm{L}-)$. Basic form sentences do not have the duncecap intonation. The sentence in (29a) is realized with regular falling pitch accents $\left(\mathrm{H}^{*}\right)$ on a mathematician and on a physicist. Second, it is a property of right node raising that the constituent that undergoes rightward across-the-board movement must be a single constituent (Bresnan 1974:615). There are plenty of basic form sentences that, for this reason, cannot be analyzed as involving full clausal coordination and right node raising. In (29b), for instance, the string girls are sunbathing on the lawn, which does not form a constituent, would have to across-the-board move.

A reviewer suggests a possible clausal coordination analysis for (29b). The NP complement of the subject determiner girls goes missing independently through noun phrase ellipsis, and then the constituent comprising are sunbathing on the lawn goes missing undergoes right node raising. Setting aside the question of intonation, this is not possible since it would be a violation of the Backwards Anaphora Constraint, which noun phrase ellipsis obeys (like other types of ellipsis). It is ungrammatical for an elided NP to precede its antecedent in a coordinate structure. Any qualms in this regard can be set aside simply by choosing a parallel basic form sentence where the determiner is one that does not license noun phrase ellipsis (every, a, no, the, etc.):

(31) Not every but some girl is sunbathing on the lawn.

Since every does not license noun phrase ellipsis, there is no ellipsis operation or combination of operations that can derive (31) from underlying clausal coordination.

Even more problematic are basic form sentences where corrective but occupies sentencemedial position. Consider, for instance, the following sentences, repeated from (16), (18), and (19) above:

(32) But the putting-forward, not of detailed and scientifically 'finished' hypotheses, but of schemata for hypotheses, has long been a function of philosophy. ${ }^{16}$

What was true, however, was that the I.O. was bound not to but from Guernsey, where she had loaded a goodly cargo of brandy and gin...

The tragedy of The Changeling is an eternal tragedy, as permanent as Edipus or Antony and Cleopatra; it is the tragedy of the not naturally bad but irresponsible and undeveloped nature, caught in the consequences of its own action.

If these examples involved full clause coordination, the constituent immediately following corrective but would be left over from removing everything else in the second clausal coordinate. But how does this remnant end up inside the first coordinate? Material from the first coordinate both precedes and follows the remnant. There is simply no parse for corrective but in sentence-medial position involving the underlying coordination of full clauses. Instead, corrective but must coordinate two PPs in (32), two prepositions in (33), and two attributive adjectives in (34).

\footnotetext{
${ }^{16}$ Hilary Putnam. 1975. Mind, language, and reality: Philosophical papers, Volume 2. Cambridge: Cambridge University Press, p. 433.
} 
Vicente considers ungrammatical sentences that superficially resemble the ones we have been considering. In (35), corrective but appears to coordinate subject DPs, and in (36) it appears to coordinate attributive adjectives.

* Two mathematicians but seven astrophysicists didn't get their papers published.

(36) * I didn't read a short but long book.

(Vicente 2010:387)

(Vicente 2010:389)

Again, these sentences cannot derive from underlying clausal coordinations since, as Vicente (2010:389) puts it, they would have to "[feature] backward ellipsis within a coordinate structure, which is not a licit operation." Why could they not involve subclausal coordination with no ellipsis, though? Because both sentences contain sentence negation. If corrective but did indeed coordinate two subject DPs in (35), its first coordinate, the DP two mathematicians, would not contain a negative element; nor would its first coordinate in (36), which would simply be the adjective short. These sentences do not have parses with subclausal coordination available, then, since they would not satisfy corrective but's requirement for a negative element in its first coordinate. Consequently, they are ill-formed.

\subsubsection{Argument 3: Subject quantifiers can take scope over corrective but in the basic form}

A reviewer offers another argument against the Clause-Only Coordination Hypothesis. Quantifiers in subject position can take scope over corrective but in the basic form:

(37) No child ate not chard but spinach.

'There was no child who did not eat chard and who ate spinach.' no $>\wedge$

At most five students drank not the whiskey but the gin.

'There were at most five students who did not drink the whiskey and who drank the gin.'

at most five $>\wedge$

The sentence in (37) is true in a state of affairs where there are no children who did not eat chard and who ate spinach. In other words, every child ate chard or did not each spinach. This is completely expected if corrective but can coordinate subclausal constituents in the scope of the subject quantifier. If corrective but only coordinated full clauses, however, this sentence should only have the stronger interpretation where conjunction takes wide scope over the quantifier no child in each conjunct. That is, no one did not eat chard, and no one ate spinach. Similarly, the sentence in (38) is true in a state of affairs where at most five students did not drink the whiskey and who drank the gin. Under the Clause-Only Coordination Hypothesis, this sentence should only have a stronger interpretation: at most five students did not drink the whiskey, and at most five students drank the gin.

\subsection{The basic form is not an 'adjacent initial edge coordination'}

Since ellipsis fails to derive the problematic corrective but sentences in (29), Vicente (2010:402403) suggests instead that these sentences are ADJACENT INITIAL-EDGE COORDINATIONS, in the sense of Bianchi and Zamparelli (2004). They are underlying full-clause coordination structures 
that look like subclausal coordination structures because they have been reduced through some other operation - specifically, movement.

From Bianchi and Zamparelli's (2004:326) very brief statement of how adjacent initial-edge coordinations are derived, I gather that (29a) would have the following structure:

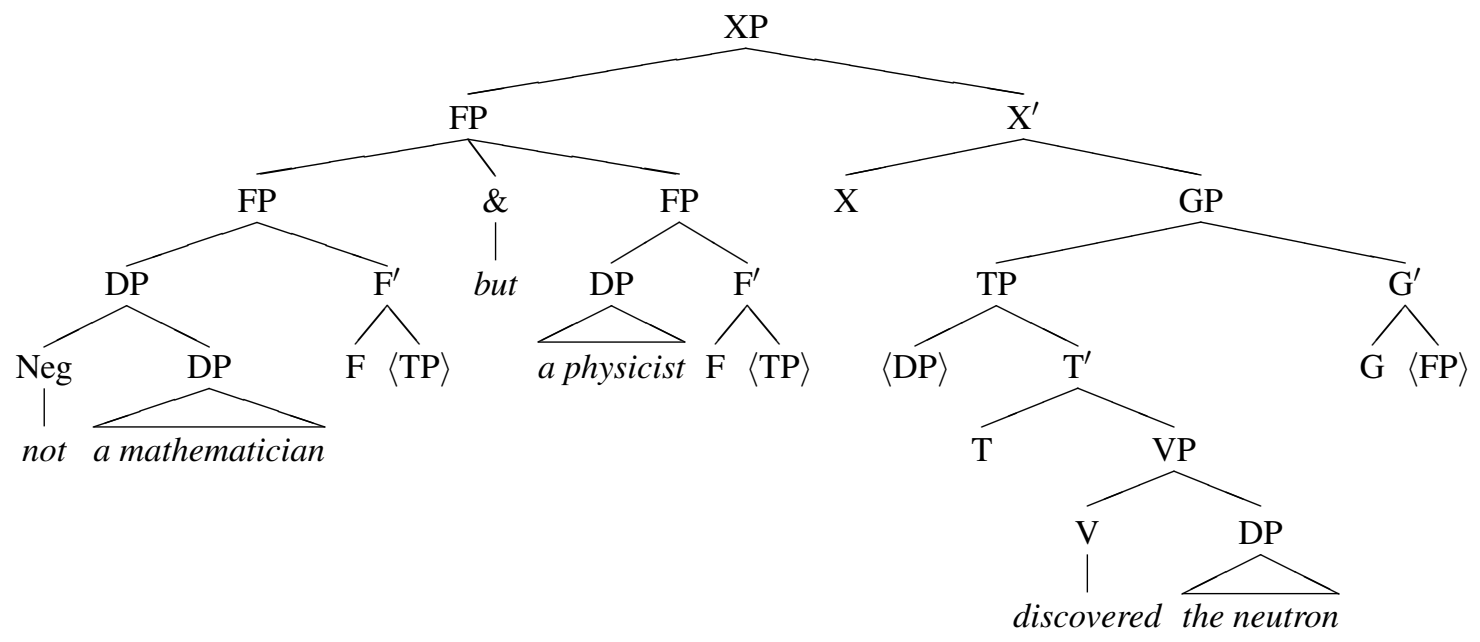

For Bianchi and Zamparelli, corrective but would coordinate two F(ocus)Ps, in the sense of Rizzi (1997). Since, from this full-clause coordination structure, they are trying to derive what looks to be subclausal coordination of subject DPs, they have to fashion a constituent that contains just corrective but and the DPs not a mathematician and a physicist. They do this by first raising the two DPs to SpecFP of their respective coordinates, and then by across-the-board remnant moving the two TPs to SpecG(round)P, a projection dedicated to backgrounded information. Finally, they have to get this constituent into a sentence-initial position, which they do by moving it into an unidentified position in the left periphery above the FP and GP projections (here, XP).

There is a very basic problem with this whole project. In a sentence like (29a), the string not a mathematician but a physicist simply does not occupy a left-peripheral position. Basic form sentences can contain a focused element in the focus position, so that corrective but and its two DPs do not occur in sentence-initial position:

THE NEUTRON, not a mathematician but a physicist discovered.

All clauses contain only one FP, as Rizzi (1997:295) shows, and the specifier of that FP in (40) is occupied by the focus-bearing direct object, the neutron. How, then, could not a mathematician and a physicist also occupy this position in their respective coordinates; and, how could the entire coordinate structure occupy an even higher left-peripheral position? If, instead, corrective but coordinates subclausal constituents, it occurs with its two DP coordinates exactly where it appears on the surface - in SpecTP.

More generally, since Bianchi and Zamparelli treat corrective but as occupying a left-peripheral position, they predict that it should only occur in sentence-initial position. This was not a problem when corrective but was coordinating subject DPs, but it frequently coordinates other kinds of subclausal constituents that, as I showed above, occupy a sentence-medial position. There is simply no way of deriving any of the sentences in (32-34) through the combination of movement processes proposed by Bianchi and Zamparelli, since given their linear position corrective but and its coordinates cannot be located in the left periphery. 


\subsection{The basic form is not a two-place determiner}

Deriving the basic form from full-clause coordination plus ellipsis or a sequence of movement operations always fails, then, since corrective but can occur anywhere in a sentence - not just in initial or final position. This essential fact about the distribution of corrective but follows completely straightforwardly if it can coordinate subclausal constituents. When, for instance, corrective but combines with two subject DPs, as in (29a), the resulting coordinate structure occupies the same sentence-initial position that subject DPs occupy normally. When it combines with two prepositions introducing a verbal adjunct, as in (33), the resulting coordinate structure occupies the same sentence-medial position. And, when corrective but combines with two object DPs, as in (10), the resulting coordinate structure occupies the same sentence-final position. To my mind, this speaks definitively against trying to assimilate corrective but's basic form to full clause coordination.

Alternately, the Clause-Only Coordination Hypothesis could be saved if in the basic form corrective but were a different lexical item than in the anchored form. This would simply remove the troublesome basic form sentences in (15-20) from the scope of the hypothesis altogether. Along these lines, a reviewer suggests that the collocation of constituent negation and corrective but that we find in the basic form is actually a single lexical item - a TWO-PLACE QUANTIFICATIONAL DETERMINER, in the sense of Keenan and Moss (1985). These are collocations like more...than..., fewer...than..., and as many ... as... that Keenan and Moss treat as complex quantificational determiners that take TWO property-type arguments (see also Beghelli 1994). In (41), the complex determiner more...than... takes the NPs students and teachers as its two arguments.

(41) The principal met with more students than teachers.

Keenan (1987) makes a concrete proposal for the internal structure of the resulting generalized quantifiers. The DP more students than teachers is a multiply-headed noun phrase (I have updated Keenan's original structure to conform to the DP Hypothesis): ${ }^{17}$

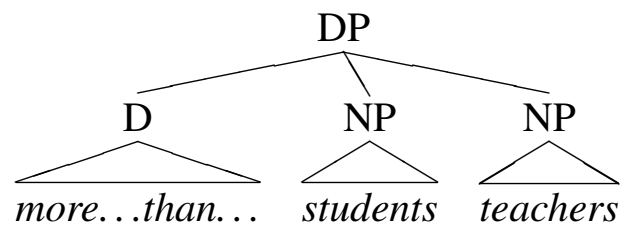

Presumably, a postsyntactic process would break apart the two parts of the complex determiner and interpolate them with the two NPs to produce the correct word order. The primary motivations for this structure are primarily semantic. More...than... and its ilk satisfy constraints on quantificational determiners, such as conservativity, and make the right predictions about how they interact semantically with predicates and nominal modifiers. ${ }^{18}$

On the face of it, it is not impossible that the collocation of not and corrective but is a complex quantificational determiner, at least in some basic form sentences. After all, the bare nouns chard and spinach in (10) might plausibly be parsed as NPs, so that the entire sentence has the following structure:

\footnotetext{
${ }^{17}$ Alternately, if ternary branching is too much, Keenan (1987:481) suggests that the two NP constituents could form a constituent together with the determiner as its sister.

${ }^{18}$ I think that we should be concerned - as Keenan is himself (see the discussion on p. 489f.) — that all of the arguments for the structure in (42) are semantic in nature. He provides no syntactic arguments, and I suspect that one would be hard pressed to find any such arguments.
} 


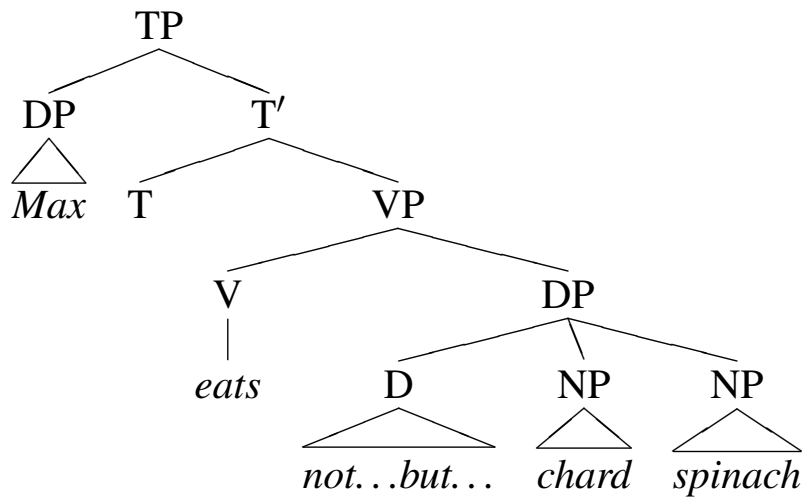

This analysis cannot, however, be generalized to ANY of the basic form sentences in (15-20). In these examples, the two constituents being combined by not and corrective but CANNOT be parsed as NPs. For instance, we find corrective but unambiguously combining entire DPs, as in (44a) or the naturally occurring example in (15). When the two-place determiner more...than. . . appears with two DP sisters, though, the result is ungrammatical, as shown in (44b). ${ }^{19}$ Moreover, corrective but can combine directly with two determiners, as in (45a); this is completely ruled out, however, with more. ..than..., as shown in (45b).

a. Not a mathematician but a physicist discovered the neutron.

b. * More a mathematician than a physicist discovered the neutron.

a. Not three but four girls are sunbathing on the lawn.

b. * More three than four girls are sunbathing on the lawn.

Even more striking are the examples in (16-20), in which corrective but is flanked by such constituents as two prepositions or two attributive adjectives. Determiners - even two-place ones simply do not have this distribution. Neither (44a), (45a), nor any of the examples in (16-20) are problematic if corrective but coordinates subclausal constituents of various categories.

This approach, moreover, treats not and corrective but as a single, fixed expression, even though this collocation of lexical items arises through the interaction of independent principles. Recall that corrective but requires a negative element somewhere inside its first coordinate because of how sentences containing corrective but interact with an (implicit) question. This pragmatic constraint can be satisfied by sentence negation when corrective but coordinates larger constituents (the anchored form) or by constituent negation when it coordinates smaller constituents (the basic form). But it can also be satisfied by a variety of other negative expressions, including negative determiners like no (46) or neither (47) and the bipartite negative coordinator neither...nor (48) (see Toosarvandani 2010:42ff. for additional examples). ${ }^{20}$ Note that, since negation is not present, corrective but belongs to neither the basic nor the anchored form in these examples.

\footnotetext{
${ }^{19}$ Note that (44b) and (45b) do have somewhat unrealistic METALINGUISTIC COMPARATIVE interpretations, in which the speaker conveys, roughly, that it is more appropriate to say that the principal met with the students than to say that she met with the teachers. The metalinguistic comparative has the same form as other degree comparatives in English, though not the same distribution - it is crosscategorial — and for this reason it is assigned a different syntax in the still-developing literature on the construction (Giannakidou and Stavrou 2009; Giannakidou and Yoon 2011; Morzycki 2011).

${ }^{20}$ The negative determiner kein in German is often decomposed into negation and an indefinite determiner because these two components, while they might be pronounced as a single phonological word, are able to take scope independently (Jacobs 1980). A reviewer suggests that, if negative determiners and coordinators in English were decomposed
} 
(46) He shared some of Plato's misgivings about democracy; but, because he was no recluse but a man of the world acquainted with public affairs, he declared his preference for limited democracy, 'polity', over other forms of government. ${ }^{21}$

With which we hope the customer buys a $331 / 3$ phonograph and a flock of records, a 45 phonograph and an equally large supply of records, or neither one but a pile of his favorite artists on 78 r.p.m., pays the dealer in cash, and walks out humming gaily. ${ }^{22}$

Most of these moves were admittedly stopgap; e.g., it is entirely possible that neither Jupiter nor Thor but the Navy's solid-fuel Polaris is the IRBM of the near future. ${ }^{23}$

These are all instances of corrective but, and not counterexpectational but. In (46), there is no expectation that, if someone is not a recluse, then they are not a man of the world; nor does (47) convey the expectation that, if the customer does not buy either a $331 / 3 \mathrm{rpm}$ or $45 \mathrm{rpm}$ phonograph, they will not buy a pile of $78 \mathrm{rpm}$ records; and, finally, there is no expectation in (48) that, if the IRBM of the future is not the Jupiter or Thor rockets, then it is not going to be the Polaris rocket.

The Clause-Only Coordination Hypothesis could have been maintained if basic form sentences were excluded from its purview by treating them as involving a different lexical item altogether. Since corrective but sounds and means the exact same thing in both the basic and anchored forms, such a strategy seems unlikely from the start. The only remotely plausible possibility, suggested by a reviewer, is that corrective but is a two-place determiner in the basic form. This analysis fails, though, since corrective but does not have the distribution of such a determiner, and since the relationship between corrective but and the negative element in its first coordinate is not a fixed, lexical one. Instead, I conclude that corrective but coordinates constituents of different sizes. Since corrective but's first coordinate must contain a negative element, it can show up with constituent negation, as in the basic form (10), and sentence negation, as in the anchored form (9), though it can also occur with negative elements like negative determiners or coordinators.

into sentence negation and another meaning component, the examples in (46-48) could have the same underlying structure as anchored form sentences, which for Vicente would involve full clause coordination and ellipsis.

There are a few considerations that, to my mind, militate against such an approach. First, it is not clear that in English the negative determiner no exhibits the same behavior as German kein. Potts (2000) shows that, while the negation in no is not able to take independent scope over a universal quantifier in subject position, it can do so for the modal need. And, even if it did, lexical decomposition is not the only way of treating the split readings found in German (see Geurts 1996 and de Swart 2000, among others). Most importantly, however, no can occur with corrective but in sentence-medial position:

(i) He taught no recluse but a man of the world his preference for limited democracy.

In (i), corrective but must be coordinating two DPs, as I argued in Section 2.1.2. Similar examples are easily created for the other negative elements in (46-48).

21 'History of education.' 1998. The New Encyclopadia Brittanica, 15th edition.

${ }^{22}$ Joe Caida. 'Let's not get dizzy on new record speeds; they're here.' The Billboard, January 15, 1949 , p. 3.

23 'Defense: The organization man.' Time Magazine, January 13, 1958. Accessed from http://www.time.com/time/ magazine/article/0,9171,862823.html. 


\section{Three syntactic counterarguments}

I now consider three potential counterarguments to my proposal that corrective but coordinates constituents of different sizes, including subclausal ones. The first two attempt to show that, when corrective but coordinates DPs, it does not behave like more canonical coordinators with respect to subject-verb agreement (Section 3.1) and binding (Section 3.2). The final counterargument attempts to show that, when corrective but coordinates subclausal constituents, it allows for extraction of a coordinate (Section 3.3), which should be ruled out by the Coordinate Structure Constraint. I show that none of these syntactic counterarguments go through.

\subsection{Subject-verb agreement}

Vicente observes that, when corrective but appears to coordinate two DP subjects, as in (49), the verb agrees in singular number. This differs from and, which triggers plural verbal agreement on the verb, as in (50).

$$
\text { Not a boy but a girl }\left\{\begin{array}{c}
\text { is } \\
* \text { are }
\end{array}\right\} \text { sunbathing on the lawn. }
$$

(Vicente 2010:402)

$$
\text { A boy and a girl }\left\{\begin{array}{c}
* \text { is } \\
\text { are }
\end{array}\right\} \text { sunbathing on the lawn. }
$$

Since corrective but does not pattern like the more canonical coordinator and in this respect, Vicente concludes it does not coordinate subclausal constituents.

But verb agreement with coordinated subjects is more complex than Vicente's original counterargument would suggest. Not all coordinators behave identically. While and can control plural agreement, or and neither...nor... control singular agreement:

$$
\begin{aligned}
& \text { A boy or a girl }\left\{\begin{array}{c}
\text { is } \\
* \text { are }
\end{array}\right\} \text { sunbathing on the lawn. } \\
& \text { Neither a boy nor a girl }\left\{\begin{array}{c}
\text { is } \\
* \text { are }
\end{array}\right\} \text { sunbathing on the lawn. }
\end{aligned}
$$

As McCawley (1998:301) observes, and pools the properties of its arguments for the purposes of determining verb agreement, while other coordinators, like or and neither...nor..., require that the verb agree with each of their arguments individually. Contrastive but could simply fall into this latter class of coordinators, and so verb agreement shows nothing about the types of constituents it coordinates. $^{24}$

\subsection{Binding}

If corrective but coordinates DPs directly, then these coordinates would not c-command out of the coordinate structure. The following paradigm of binding data, suggested by a reviewer, might then seem problematic:

\footnotetext{
${ }^{24}$ Ideally, as a reviewer points out, we would want an explanation for why corrective but patterns with or and neither...nor. .., rather than and, with respect to verb agreement. I agree, but I leave this for future research.
} 

a. Not Alice but Bob B taught himself $_{1}$ calculus.
b. * Not Alice but Bob 1 taught him 1 calculus.
c. * Not Alice but he 1 taught Bob $_{1}$ calculus.

Corrective but coordinates the two DPs not Alice and Bob. Yet, in (53a), the second DP manages to bind a reflexive pronoun in object position. (Note that the sentence is grammatical only if Alice is construed as a male individual. ${ }^{25}$ ) The second DP coordinate can also trigger Condition B and $\mathrm{C}$ violations, as shown in (53b) and (53c) respectively.

The interaction between binding and coordination is more complicated, however, than the most basic version of Binding Theory would suggest. Consider, for instance, the parallel sentences in (54), which substitute or for corrective but. They show the exact same binding pattern.
a. Alice or Bob ${ }_{1}$ taught himself 1 calculus.
b. * Alice or Bob 1 taught him 1 calculus.
c. $*\left\{\begin{array}{c}\text { Alice or him } \\ \mathrm{He}_{1} \text { or Alice }\end{array}\right\}$ shaved Bob 1 .

Even though the second coordinate $B o b$ does not c-command out of the coordinate structure, it can bind a reflexive pronoun in object position (54a). (Again, Alice is presupposed to be a male individual.) And, it produces Condition B and $\mathrm{C}$ violations (54b-c).

Corrective but behaves just like other coordinators with respect to binding, and so the pattern in (53) does not comprise an argument against corrective but coordinating subclausal constituents. Instead, the data in (53-54) simply show that Binding Theory must be elaborated more generally to account for coreference patterns in subclausal coordination structures.

\subsection{Coordinate Structure Constraint}

Vicente (2010:314) observes that some apparent cases of subclausal coordination with corrective but do not seem to obey the Coordinate Structure Constraint. In (55a), what looks like corrective but's first DP coordinate has moved to sentence-initial position. I see no principled reason why only and also are included in this example, since without them, as in (55b), the sentence is still grammatical.

a. Not only Mary did he invite, but also Lucy.

(Vicente 2010:402)

b. Not Mary did he invite, but Lucy.

If $(55 a-b)$ involved subclausal coordination, the first clause of the Coordinate Structure Constraint, which disallows extraction of coordinates (Ross 1967:161), would be violated. Vicente concludes that corrective but therefore cannot coordinate subclausal constituents.

But as in Vicente's treatment of the anchored form, when corrective but occurs in sentence-final position, the sentence could involve underlying clausal coordination and ellipsis. Such a derivation for the sentence in $(55 \mathrm{~b})$ would produce the following structure:

\footnotetext{
${ }^{25}$ The reviewer consulted three native speakers of English who disagree with my judgement that Alice must exceptionally be taken to be male. There appears to be some dialectical variation on this point.
} 
(56)

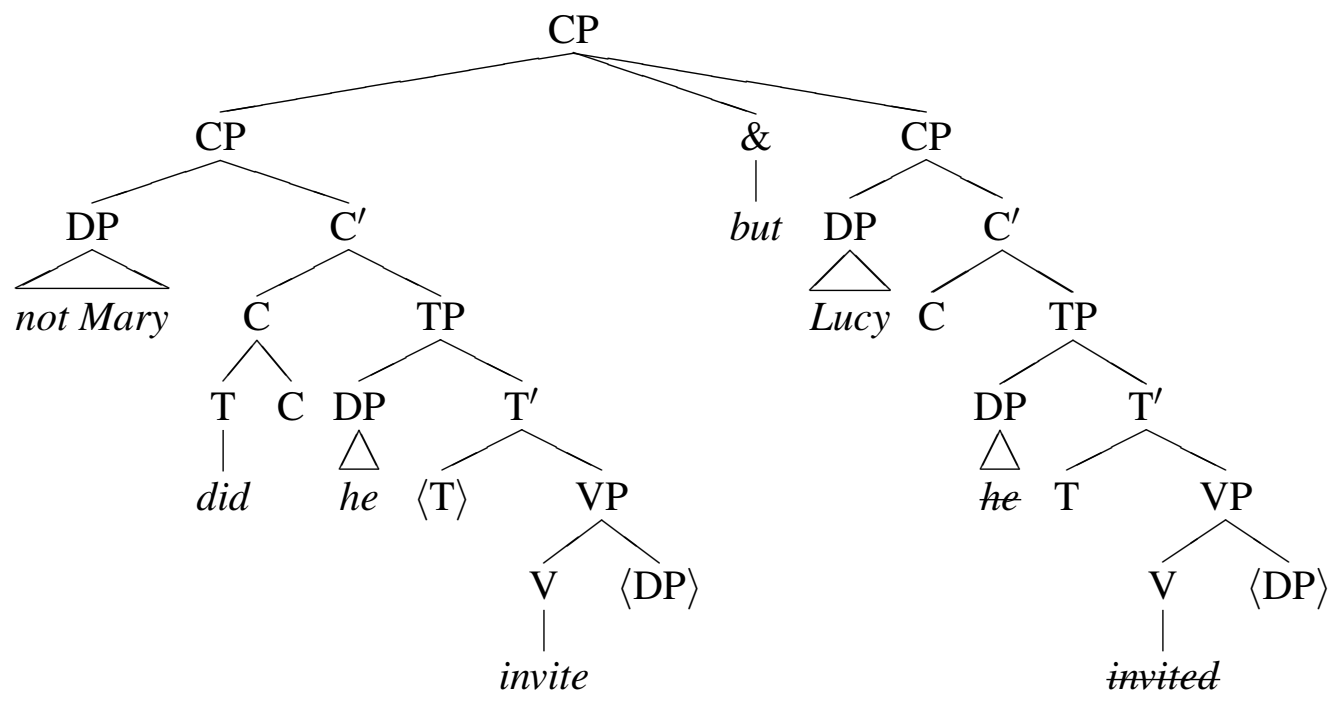

Constituent negation is adjoined to the object DP Mary, which satisfies corrective but's requirement for a negative element in its first coordinate. This negated DP fronts to SpecCP, triggering subjectauxiliary inversion. The second coordinate is reduced to the remnant Lucy by ellipsis. As expected, the topicalized DP in the first coordinate exhibits all the signs of having undergone $\mathrm{A}^{\prime}$-movement:
a. $\quad[$ DP Not (only) herself 1$]$ did Mary 1 invite $\langle\mathrm{DP}\rangle$ but (also) Lucy.
b. $\quad\left[\right.$ DP Not (only) her $\left.{ }_{* 1 / 2}\right]$ did Mary 1 invite $\langle\mathrm{DP}\rangle$ but (also) Lucy.
c. $\quad\left[\right.$ DP Not (only) Mary $\left.{ }_{* 1 / 2}\right]$ did she ${ }_{1}$ invite $\langle\mathrm{DP}\rangle$ but (also) Lucy.

The fronted DP reconstructs to satisfy Principle A (57a); a nonreflexive pronoun or R-expression contained in the fronted DP triggers Principle B and C violations in its reconstructed position $(57 \mathrm{~b}-\mathrm{c})$. And, in (58), extraction of not (only) Mary licenses a parasitic gap ( $\mathrm{pg}$ ).

Of course, there are completely unambiguous cases of subclausal coordination (as I showed in Section 2). When, for instance, corrective but occurs in sentence-medial position, it can only be parsed as subclausal coordination:

He invited not (only) Mary but (also) Lucy to the party.

In (59), corrective but must coordinate two DPs, not (only) Mary and (also) Lucy, since there is no other way of deriving its linear position between the verb and the PP modifying the verb phrase. As expected, extraction of the first DP coordinate is ungrammatical, as in (60), since it violates the Coordinate Structure Constraint. The structure for (60) is given in (61).

* Not (only) Mary did he invite but (also) Lucy to the party. 
(61)

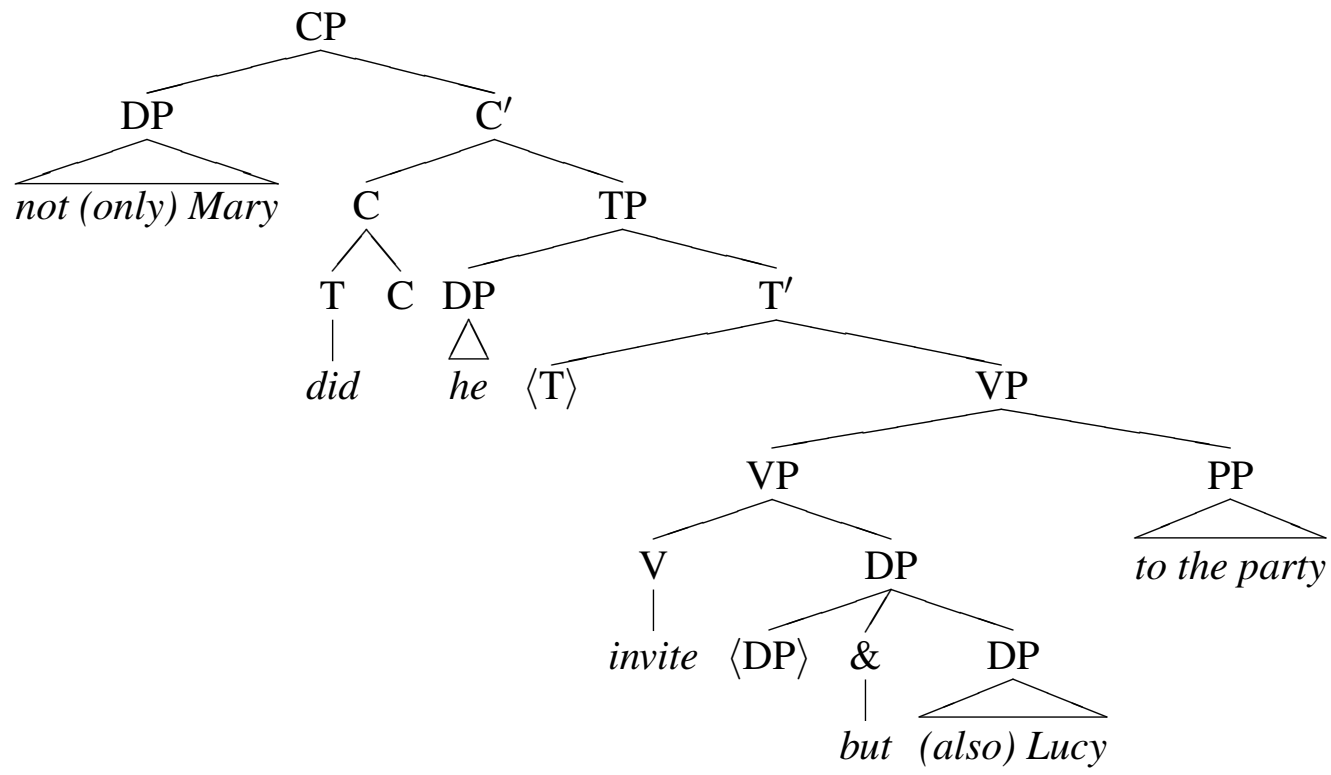

Contrary to Vicente's claim, then, corrective but does obey the Coordinate Structure Constraint when it coordinates subclausal constituents. There are some cases, like the ones in (55), where extraction seems possible, but these sentences are in fact best analyzed as involving clausal coordination and ellipsis. They thus do not comprise a counterargument to my claim that corrective but can coordinate subclausal constituents.

At this point, it should be clear that the terminological distinction between the basic and anchored forms does not correspond to any useful analytical distinction. Recall that, for McCawley, the anchored form contains sentence negation, and the basic form contains constituent negation. In the examples we have seen so far, when the first coordinate contains sentence negation, ellipsis is always involved. When it contains constituent negation, however, the second coordinate may or may not be reduced. In the sentence in (59) - like the original basic form sentence Max eats not chard but spinach - corrective but coordinates two DPs, and no ellipsis is needed to derive the surface form. In (55b), though, even though the first coordinate contains constituent negation, corrective but coordinates two full clauses, with the second clause being reduced to a DP remnant. For this reason, I will cease using McCawley's terminology in the rest of the paper.

\section{A semantic counterargument}

A reviewer offers another argument for the Clause-Only Coordination Hypothesis and correspondingly against corrective but coordinating subclausal constituents. In classical logic, negation is a truth-functional sentence operator (it takes a sentence that denotes a truth value as an argument and returns a sentence that denotes a truth value). Consequently, the argument goes, corrective but must always coordinate full clauses, since how else would negation be able to take scope just inside the first conjunct? That is, how else would all corrective but sentences translate schematically as $\neg p \wedge q ?^{26}$

\footnotetext{
${ }^{26}$ Vicente (2010:386-387) puts forward an argument that might easily be confused with this one. He observes that sentence negation never takes wide scope over conjunction in corrective but sentences. When and coordinates two DPs, it does allow for a wide-scope negation interpretation, i.e. $\neg(p \wedge q)$. Therefore, he concludes, corrective but
} 
Expressions that semantically take a truth value as an argument need not, however, have a full clause for a sister. In early transformational grammar, and was treated as always coordinating full clauses, with the superficial appearance of subclausal coordination derived by transformation (see, for instance, Chomsky 1957:35-38). Semanticists have since shown, though, that and can be given a natural meaning that maintains the truth conditions of the traditional truth-functional sentence connective while allowing for a wider syntactic distribution (Gazdar 1980; Rooth and Partee 1982; Partee and Rooth 1983). Partee and Rooth (1983:364), for instance, propose that and in English corresponds to the meet operator $\sqcap$ defined in (62). ${ }^{27}$

$$
X \sqcap Y= \begin{cases}X \wedge Y, & \text { if } X \text { and } Y \text { are truth values } \\ \lambda Z(X(Z) \sqcap Y(Z)), & \text { if } X \text { and } Y \text { are functions }\end{cases}
$$

When the meet operator's arguments are truth values, it is equivalent to classical conjunction $(\wedge)$. When its arguments are functions, however, the meet operator returns a function whose range is the meet of the two input functions' ranges. The meet operator is thus defined for functions whose range is the domain of truth values or, if the function is more complex, the innermost function's range is the domain of truth values. The truth conditions of and end up equal to those of classical truth-functional conjunction even when it coordinates subclausal constituents.

Much in the same fashion, negation can be treated as classical negation even when it adjoins to a subclausal constituent. Take the two corrective but sentences in (63), repeated from (29), which I argued cannot be analyzed as involving clausal coordination plus gapping (Section 2.1), an 'adjacent-initial edge coordination' (Section 2.2), or a complex determiner (Section 2.3).

a. Not a mathematician but a physicist discovered the neutron.

b. Not three but four girls are sunbathing on the lawn.

(Vicente 2010:400)

In these sentences, corrective but coordinates two subclausal constituents - two DPs in (63a) and two Ds in (63b). The semantic counterargument described above claims that this is impossible since negation must, if it is to take scope just inside the first conjunct, be adjoined to the first subclausal coordinate, a position where it cannot be interpreted as a truth-functional sentence operator. But it is a textbook exercise to give a lexical entry for not, when it adjoins to a DP or D, that assigns it the truth conditions of classical negation. Consider, for instance, Chierchia and McConnell-Ginet's (2000:511-514) definitions for not in (64) and (65), where it combines with a generalized quantifier or quantificational determiner respectively: ${ }^{28}$

does not coordinate DPs. This line of reasoning neglects the fact that corrective but, unlike and, has an independent requirement for there to be a negative element in its first coordinate. This constraint must satisfied even when corrective but coordinates DPs - by constituent negation or another DP-internal negative element.

${ }^{27}$ One reason and cannot always coordinate full clauses is that there are conjunctions that do not distribute:

(i) Some student lives in New Jersey and works in New York. ( $\$$ Some student lives in New Jersey, and some student works in New York.)

(Keenan and Faltz 1985:5)

(ii) Mary and John met. ( $\nRightarrow$ *Mary met, and John met.)

(Winter 2001:31)

While (i) is a paradigm example for the boolean treatment for conjunction, (ii) is not obviously accounted for by the flexible-type meet operator in (62). See Winter 2001:32-45 for a discussion of previous approaches to these cases of so-called non-boolean conjunction, as well as a proposal for assimilating such cases to the meet operator.

${ }^{28}$ For the sake of presentation, I have rewritten Chierchia and McConnell-Ginet's denotations. The lexical entries in (64) and (65) are equivalent to their entries in (32b) and (36b) on p. 514f. 


$$
\begin{aligned}
& \llbracket \operatorname{not} P \rrbracket=\lambda f(\neg P(f)):\langle\langle e, t\rangle, t\rangle \\
& \llbracket \operatorname{not} \mathscr{P} \rrbracket=\lambda f \lambda g(\neg \mathscr{P}(f)(g)):\langle\langle e, t\rangle,\langle\langle e, t\rangle, t\rangle\rangle
\end{aligned}
$$

To illustrate, take the sentence in (63), which has the following parse: ${ }^{29}$

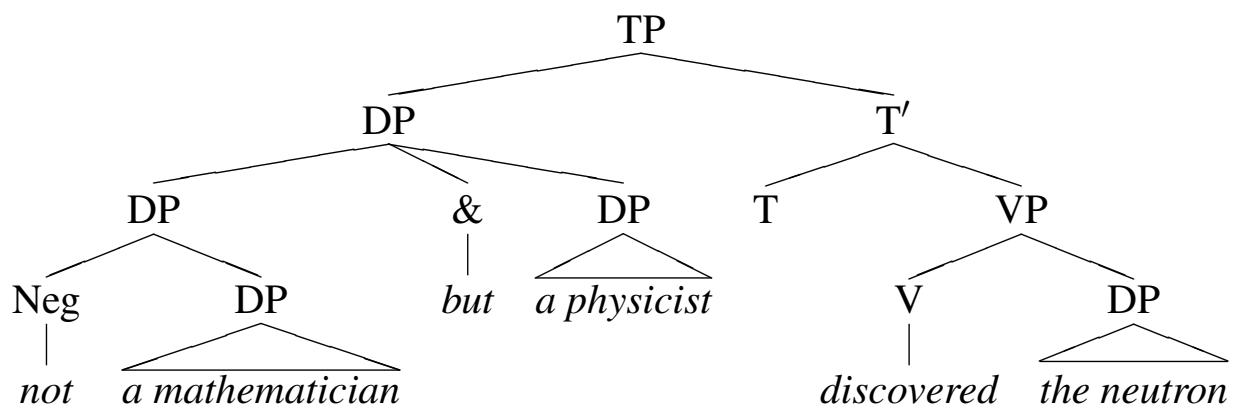

Assuming that indefinite DPs have denotations in the domain of generalized quantifiers - functions from sets of entities to truth values (type $\langle\langle e, t\rangle, t\rangle$ ) - either as their basic meaning or through type shifting (Partee 1986) — then the sentence in (63) is interpreted as in (67). Since corrective but has the same truth conditions as and, it is translated as the crosscategorial meet operator from (62).

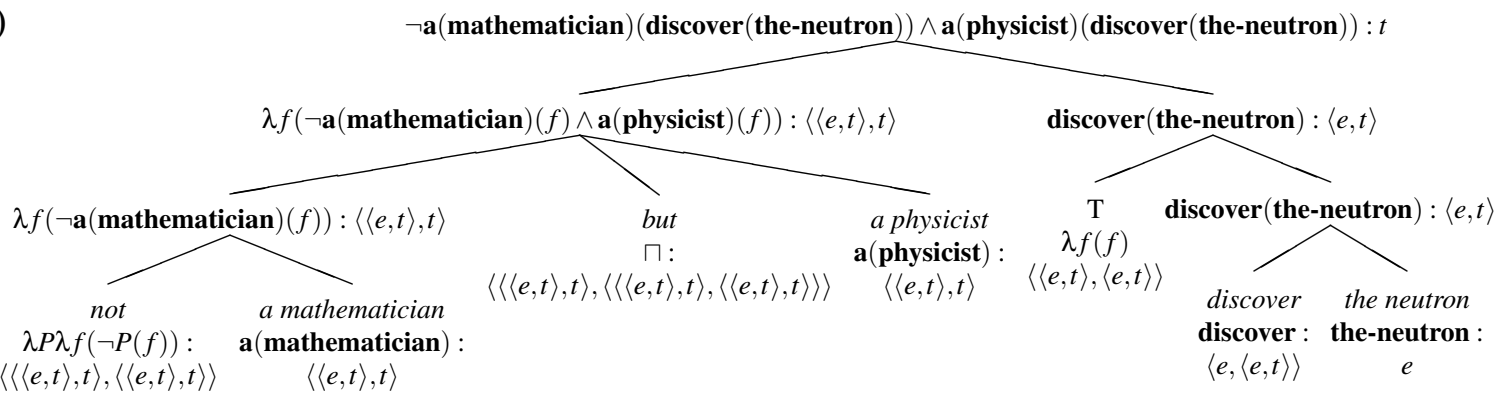

Interpreted as a generalized quantifier, the DP a mathematician denotes the set of sets containing a mathematician. Similarly, the DP a physicist denotes the set of sets containing a physicist. Negation, which adjoins to a mathematician, returns its complement: the set of sets that do not contain a mathematician. The coordination of these two DPs denotes another generalized quantifier, the set of sets that do not contain a mathematician and that do contain a physicist. This generalized quantifier takes the property denoted by the verb phrase as its argument so that the entire sentence ends up with the desired meaning: it is not the case that a mathematician discovered the neutron, and it is the case that a physicist discovered the neutron. Negation takes scope just within the first conjunct, even though syntactically it adjoins to a DP.

As we saw in Section 2, not all the basic form sentences involve DP coordination or the coordination of determiners - the coordination of PPs, prepositions, adjectives, adverbs, etc. is also possible. To interpret constituent negation when it is adjoined to these constituents, researchers in the tradition of Boolean Semantics give both sentence and constituent negation a single, unified meaning, much like that of and above (Keenan and Faltz 1985; Winter 2001). Since many natural language expressions denote in semantic domains that have the properties of a boolean algebra,

\footnotetext{
${ }^{29}$ Rothstein (1988) argues that, in examples like Not every student passed, constituent negation does not adjoin to the sentence-initial generalized quantifier, but to the root node of the sentence. It is clear, however, that negation forms a constituent with the DP subject: i.e. Not every boy and not every girl passed.
} 
and can be treated as the boolean meet operator, much as in Partee and Rooth's definition in (62), and or can be treated as the boolean join operator. Negation, then, corresponds to the boolean complement operator, which can be represented as in (68). (This is simply a restatement of Winter's (2001:23) flexible-type complement operator so that it is parallel in form to (62).)

$$
-X= \begin{cases}\neg X, & \text { if } X \text { is a truth value } \\ \lambda Y(-X(Y)), & \text { if } X \text { is a function }\end{cases}
$$

When the complement operator takes a truth value as an argument, it is interpreted as classical negation $(\neg)$. When it takes a function as an argument, it returns a function whose range is the complement of the original function's range. By introducing the complement operator recursively in this way, the truth conditions of not are equivalent to classical, truth-functional negation, regardless of whether it combines with a full clause or some subclausal constituent.

Two reviewers worry that this treatment of negation and its relationship to corrective but does not account for the intuition - often alluded to, but not fully substantiated - that constituent negation, unlike sentence negation, cannot stand on its own but requires a continuation with corrective but:

$$
\text { Max eats not chard \#(but spinach). }
$$

Removing corrective but and the second DP coordinate in (69) is, I grant, infelicitous. But it is simply not the case that constituent negation never stands on its own. The classic examples of constituent negation, from Klima's (1964) seminal paper, occur perfectly felicitously without a continuation:

(70) a. He found something interesting there not long ago.

b. He had spoken with someone else not many hours earlier.

c. There was some rain not long ago.

d. He married a not unattractive girl.

e. Writers not infrequently reject suggestions.

f. He is content with not 200 a year.

g. Not a few authors criticized him severely.

(Klima 1964:305)

Moreover, even when constituent negation does occur with a continuation, this does not have to involve corrective but. The continuations of PP-adjoined constituent negation in (71-72) are introduced by rather and instead.

(71) Though he spoke not in anger — rather in infinite sadness - he fairly turned her out. ${ }^{30}$

(72) Saturday was my last full day in Nipton. So, of course The Raven and I spent most of the day not in Nipton. Instead, we headed for the Mitchell Caverns in the Providence Mountains... 31

\footnotetext{
${ }^{30}$ Henry James. 1902. The wings of the dove. New York: Charles Scribner's Sons, p. 24.

${ }^{31}$ http://faultline.org/index.php/site/item/not_to_scale/, April 8, 2011.
} 
Thus, there is no logical dependency between constituent negation and corrective but. The former can occur without the latter (70-72), and the latter can occur without the former (46-48).

While aspects of the use of constituent negation remain mysterious, what is relevant for our discussion of the syntax of corrective but is simply the meaning of constituent negation. It is clear that constituent negation has the same truth conditions as sentence negation, even in examples like (71-72) where there is a continuation. The author in (71) conveys that it is not the case that he spoke in anger; and, in (72), the author expresses that it is not the case that he spent most of the day in Nipton. ${ }^{32}$ These truth-value-reversing semantics for constituent negation are captured by Chierchia and McConnell-Ginet's definitions for not in (64-65) and by the crosscategorial entry in (68). It is thus possible to interpret not when it combines with subclausal constituents with the same truth conditions as the classical truth-functional sentence operator. Therefore, the interpretation of negation does not provide an argument against corrective but coordinating subclausal constituents.

\section{The reduction operation}

So far, I have not said much about what the reduction operation active in corrective but sentences is. Vicente assumes that it is ellipsis applied to CP coordination structures (since, of course, he assumes the Clause-Only Coordination Hypothesis). In most current thinking, ellipsis is a deletion operation that takes place at the level of PF (Merchant 2001). It can apply to constituents of different sizes to derive verb phrase ellipsis (73), sluicing (74), and noun phrase ellipsis (75).

(73) Max has made key lime pie before, and Sam has fvp made key lime pie before], too. Liz kissed someone at the party, but she doesn't know who [TP Liz kissed (who)]. I bought the red convertible, and Sam bought the blue [NP convertible].

In verb phrase ellipsis, a vP is deleted under identity with a preceding vP, as in (73). In sluicing, the TP in a constituent question is deleted, leaving the wh-phrase behind, as in (74). In noun phrase ellipsis, an NP is deleted under identity with a preceding NP, as in (75).

\footnotetext{
${ }^{32}$ For precisely this reason, the metalinguistic meaning that Giannakidou and Stavrou (2009:71f.) give to the marker of constituent negation in Greek, oxi, cannot be correct for English constituent negation (see also Giannakidou 1998:50f.). They take oxi to be a two-place operator on propositions, conveying that it is not correct for an individual $\alpha$ to say the first proposition but that it is correct for $\alpha$ to say the second one:
}

$$
\begin{aligned}
& \llbracket \text { oxi } \rrbracket=\lambda p \lambda q(\neg R(\alpha)(p) \wedge R(\alpha)(q)) \\
& \text { where } R \text { is the attitude 'correct to say' }
\end{aligned}
$$

(Giannakidou and Stavrou 2009:71)

Given this lexical entry, constituent negation would only express something about the ATTITUDE of an individual $\alpha$ towards two propositions. But as I discuss in the text, all of the examples in (69-72) in fact express something about the truth or falsity of a proposition at a world of evaluation. This is nothing more than the truth-reversing semantics of classical negation.

There are three additional reasons why Giannakidou and Stavrou's semantics for Greek oxi cannot be extended to English constituent negation. First, constituent negation does not always occur with a continuation, as in (70a-g). Such a continuation is, however, required by the two-place function in (i). Second, even when constituent negation does have a continuation, it does not, as in (72), have to be contained in the same sentence. The lexical entry in (i) requires both propositions to occur inside the same sentence so they can combine compositionally. And, third, the lexical entry in (i) fixes the relationship of the two propositions in terms of 'correctness to say'. But in (72), the author CLEARLY is not expressing that it is incorrect to say that they spent the day at Nipton — he is simply contrasting spending time in Nipton on their last day with spending time elsewhere. 
The reduction operation in corrective but sentences does not look like any of these phenomena. In the corrective but sentences that Vicente was originally interested in, such as (76), repeated from (9) above, it is not a constituent that goes missing but everything in the second coordinate except for the remnant DP spinach.

$$
\text { Max doesn't eat chard, but spinach. }
$$

Instead, Vicente invokes a thread of the ellipsis literature, originating with Merchant (2004), that treats fragment answers to questions as arising from the application of ellipsis to a full clause. The corrective but sentence immediately above would, under this view, involve movement of the remnant to a left-peripheral position, such as SpecCP, followed by TP ellipsis:

$$
\text { [CP [CP Max doesn't eat chard] but [CP [DP chard] [TP Max eats (chard)]]. }
$$

But there is a difficulty with treating this sentence as involving coordination of CPs and ellipsis of TP. Identity is required between the constituent that is deleted and its antecedent. In Section 5.1 below, I show that, since in (76) corrective but contains sentence negation in its first coordinate, the $\mathrm{TP}$ of the second coordinate is not identical to the TP of the first coordinate. Thus, the derivation of (76) cannot involve full clausal coordination and ellipsis, though there are other corrective but sentences that do. While Vicente focuses on the analogy to fragment answers, the remnant in (76) actually has a closer profile to gapping. In Section 5.2, I consider whether a popular treatment of gapping — small coordination with across-the-board movement (Johnson 2004, 2009) — can be extended to corrective but. ${ }^{33}$ It cannot. But as I suggest in Section 5.3, an ellipsis account of the sentence in (76) is possible if corrective but coordinates vPs. Such a small coordination plus ellipsis analysis has been proposed elsewhere for gapping more generally (Coppock 2001; Lin 2002). To derive corrective but sentences like (77), then, ellipsis must be able to apply to subclausal coordination structures - contra the Clause-Only Coordination Hypothesis.

\subsection{Ellipsis}

Vicente treats the reduction operation found in corrective but sentences as ellipsis of a full clause, along "the lines of [Merchant $(2001,2004)]$ and related work - that is, in terms of movement of the remnant of ellipsis to the left periphery plus PF deletion of IP" (2010:382). The remnant in corrective but sentences, in other words, arises in the same way that Merchant (2004) proposes fragment answers do. The remnant raises to a left-peripheral position, such as SpecCP, and TP deletes at PF. Since the TP is elided under identity with an antecedent TP, the fragment answer conveys the appropriate propositional content. The relevant identity condition can be stated as

\footnotetext{
${ }^{33}$ There are a few minority theories of gapping, including nonconstituent deletion (Ross 1970; Hankamer 1973; Sag 1976; Hankamer 1979; Neijt 1979; van Oirsouw 1987; Wilder 1994, 1997; Hartmann 2001), sharing (Moltmann 1992), copying (Repp 2009), and base-generation of remnants (Sag et al. 1985; Oehrle 1987; Culicover and Jackendoff 2005). I do not consider them for reasons of space.
} 
follows, which is a simplified version of Merchant's (2001:26) eGIVENness identity constraint:

IDENTITY CONSTRAINT ON ELLIPSIS

An elided phrase $\mathrm{XP}_{E}$ must have an antecedent phrase $\mathrm{XP}_{A}$, such that modulo $\exists$-binding of any traces in $\mathrm{XP}_{E}$ and $\mathrm{XP}_{A}$ :

(i) $\mathrm{XP}_{E}$ entails $\mathrm{XP}_{A}$, and

(ii) $\mathrm{XP}_{A}$ entails $\mathrm{XP}_{E}$.

The elided and antecedent phrases must mutually entail each other, modulo existential quantification over the traces of movement (which are interpreted as free variables).

Let's look at how the identity constraint works out for (76), which Vicente assumes involves movement of the remnant in the second coordinate to SpecCP followed by ellipsis of TP:

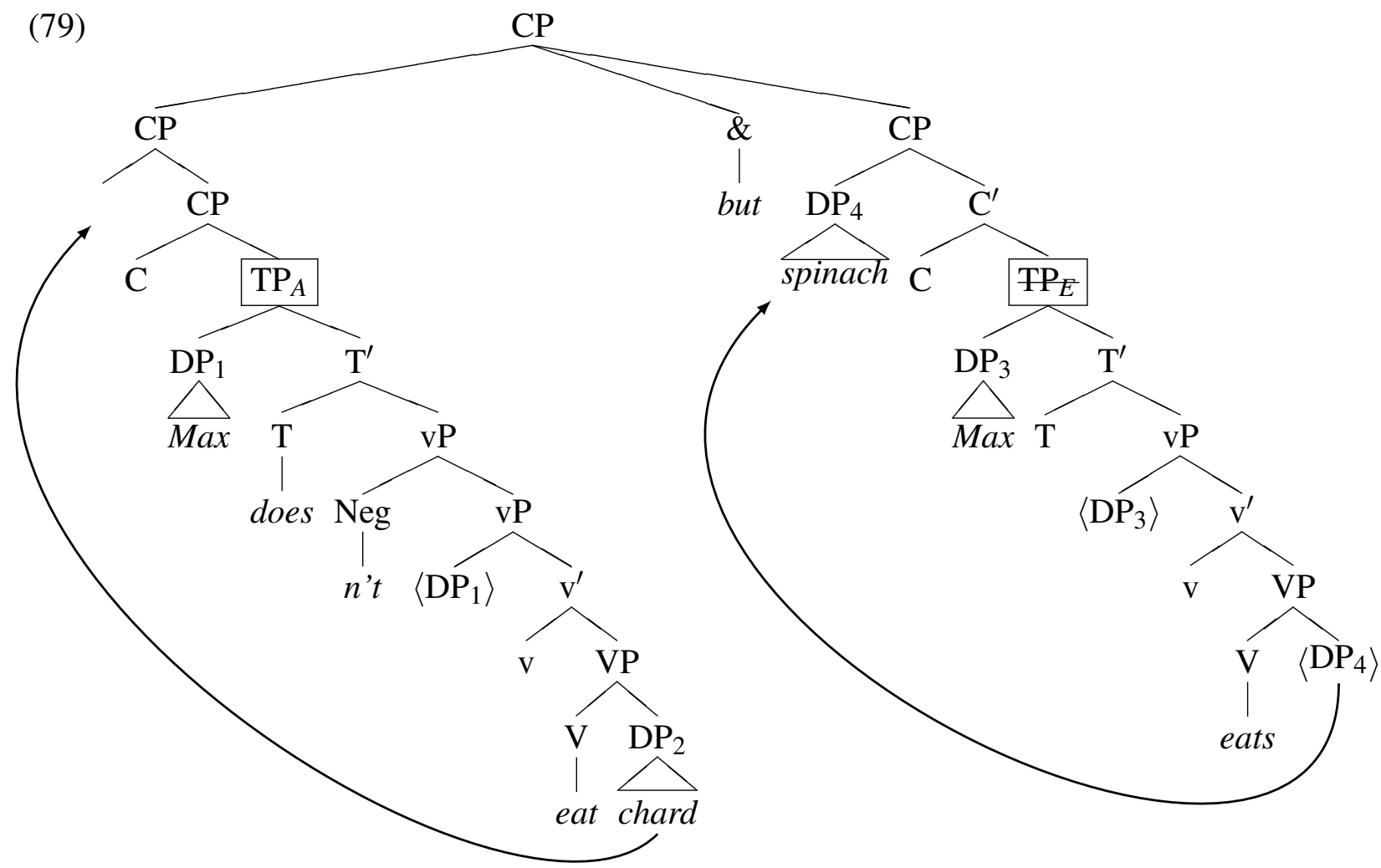

To calculate identity between the antecedent and elided TPs, the correlate of the remnant in the antecedent must be factored out. Merchant (2008:148f.) assumes this can happen through LF movement. Parallel to overt movement of $\mathrm{DP}_{4}$ spinach in the second coordinate, $\mathrm{DP}_{2}$ chard in the first coordinate raises covertly to a left-peripheral position (indicated with an arrow originating in $\mathrm{DP}_{2}$ 's pronounced position).

Even so, the identity constraint on ellipsis is not satisfied in (79), because the first coordinate contains sentence negation, which occurs at the left edge of the verb phrase. The antecedent and elided TPs thus do not entail each other:

$$
\begin{array}{rlrl}
\text { a. } & & \llbracket \mathrm{TP}_{A} \rrbracket & =\exists x(\neg \mathbf{e a t}(x)(\mathbf{m a x})) \\
\text { b. } & \llbracket \mathrm{TP}_{E} \rrbracket & =\exists x(\operatorname{eat}(x)(\mathbf{m a x}))
\end{array}
$$


If there is something that Max does not eat, it does NOT follow that there is something that he does eat. And, if there is something that Max does eat, it does NOT follow that there is something that he does not eat. The corrective but sentences that Vicente was originally concerned with thus cannot involve coordination of full clauses (CPs). Since the first coordinate contains sentence negation, the identity constraint on ellipsis is not satisfied - the antecedent and target TPs are not identical.

There are, however, corrective but sentences that involve full clausal coordination. Recall that, while (81), repeated from (55b) above, might seem to violate the Coordinate Structure Constraint, I argued that it has the structure in (82). The negative element in the first coordinate is constituent negation, even though corrective but coordinates two CPs.

Not Mary did he invite, but Lucy.

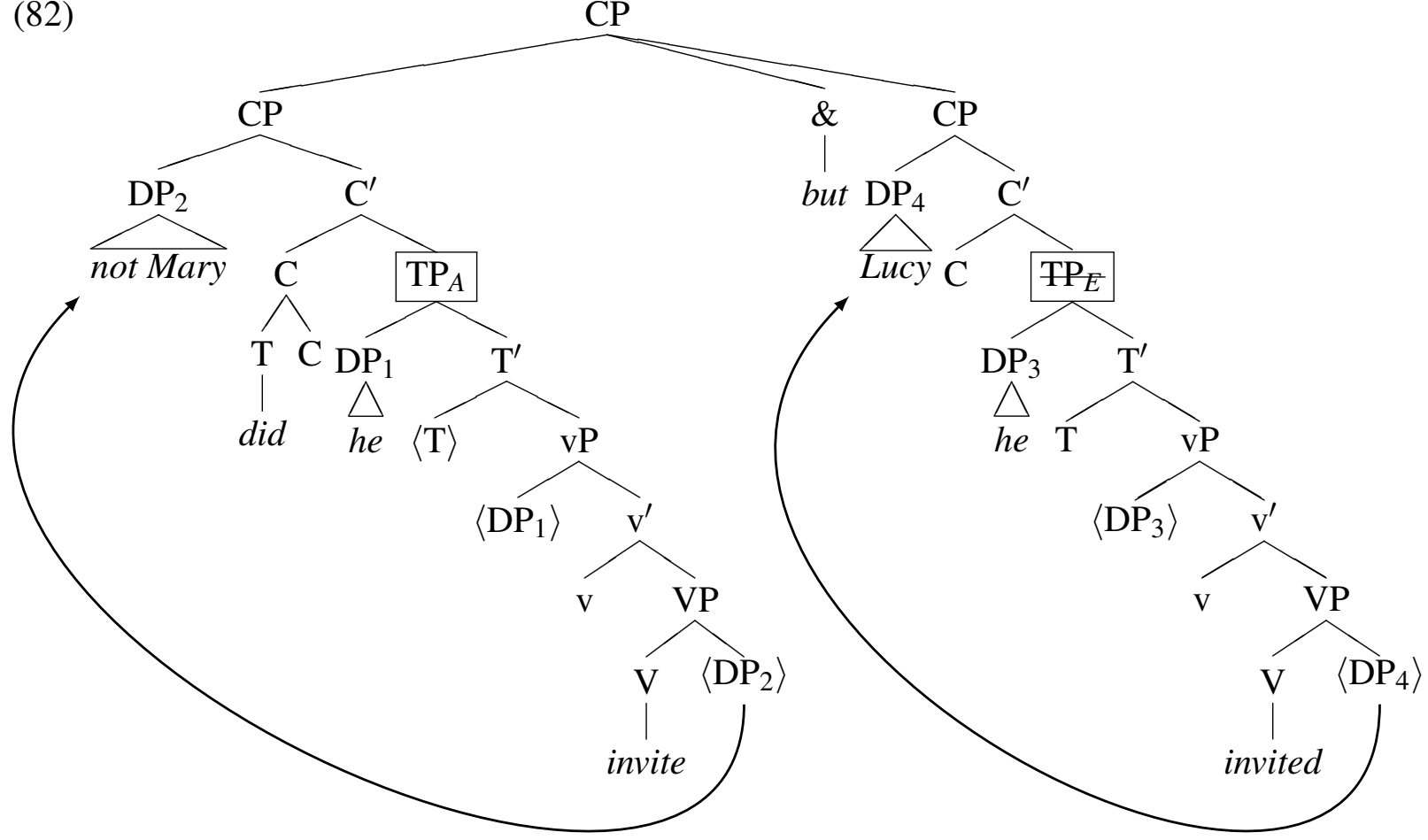

Since the direct object DPs not Mary and Lucy have raised overtly to SpecCP in their respective coordinates, the elided and antecedent TPs are identical. Modulo $\exists$-binding of the traces of these DPs, we can see that $\mathrm{TP}_{A}$ and $\mathrm{TP}_{E}$ entail one another:

$$
\begin{aligned}
\text { a. } & \llbracket \mathrm{TP}_{A} \rrbracket & =\exists x(\text { invite }(x)(\text { he })) \\
\text { b. } & \llbracket \mathrm{TP}_{E} \rrbracket & =\exists x(\text { invite }(x)(\text { he }))
\end{aligned}
$$

Constituent negation in the first coordinate does not enter into the identity calculation since it is adjoined to the direct object DP, which has been extracted from the antecedent phrase. 


\subsection{Across-the-board movement}

While Vicente draws a parallel between the remnant in corrective but sentences and fragment answers, they have a profile that resembles gapping, which is illustrated in (84-85). ${ }^{34}$

Max brings gin to parties, and vodka, too.

Sam often brings an apple for the teacher, and a browny for the principle.

In (84), everything in the second coordinate of a coordination structure has gone missing except for a single phrase, the DP vodka; in (85), everything in the second coordinate has gone missing except for two phrases, the DPs Liz and brownies. The reduction operation in corrective but sentences similarly can leave behind two remnants:

Sam didn't bring an apple for the teacher, but a browny for the principle.

In Johnson's $(2004,2009)$ influential theory of gapping, small coordination structures - coordination of just vPs - underly the sentences in (84-85). Everything in the second vP coordinate goes missing - not through ellipsis but because the vPs in both coordinates undergo across-theboard movement. The gapping sentence in (84) with one remnant has the following structure:

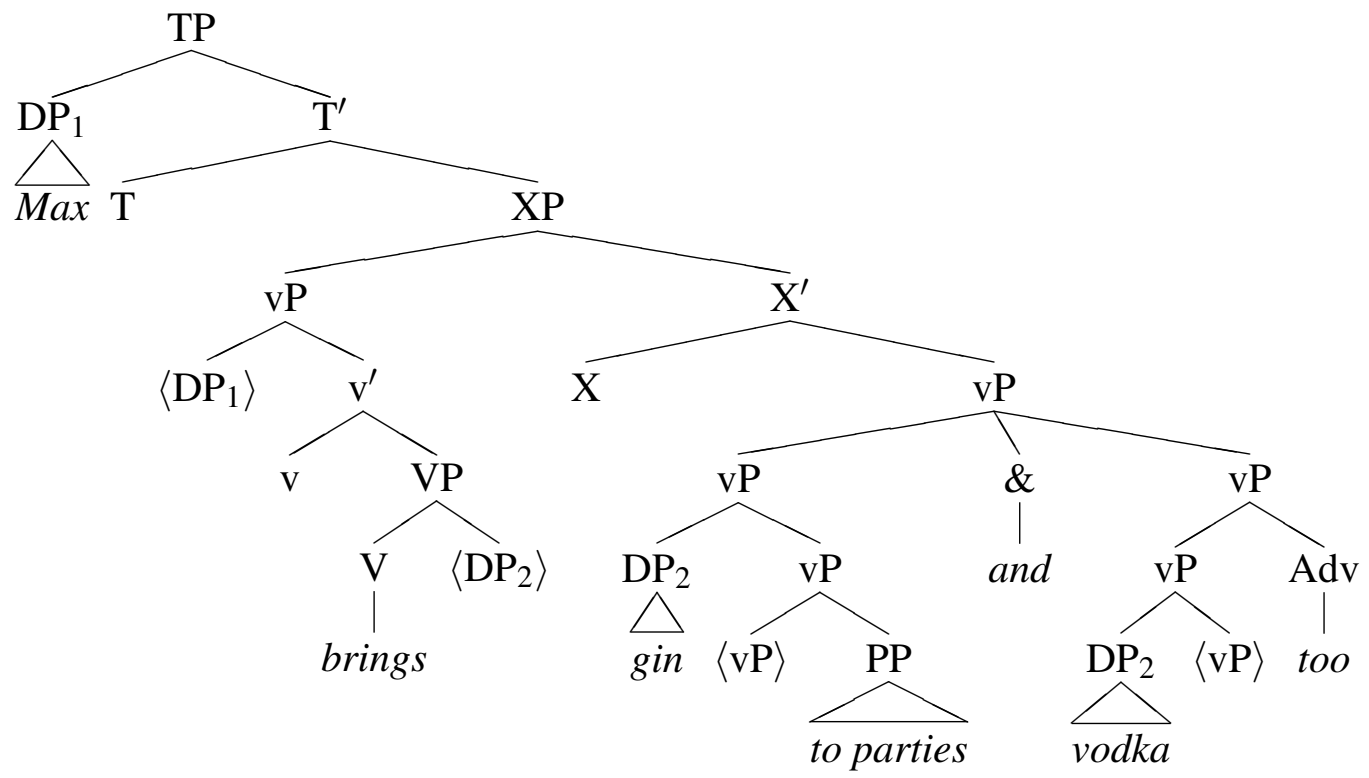

This derivation proceeds in three steps. First, the remnant, $\mathrm{DP}_{2}$ vodka, and its correlate in the first coordinate, $\mathrm{DP}_{2}$ gin, raise to adjoin to the vPs containing them. Second, the two vPs - which are now identical because they no longer contain those DPs - undergo across-the-board movement to the specifier of a functional projection located immediately above the coordination (here, SpecXP). Third, and finally, the subject, $\mathrm{DP}_{1}$ Max, raises out of the vP to SpecTP.

Such a derivation is not, however, possible for the corrective but sentence in (76), since it does not derive the correct linear order of the verb and negation. For (76), corrective but would

\footnotetext{
${ }^{34}$ The ellipsis operation in (84) sometimes goes by the name stripping (or bare argument ellipsis). Following Johnson (2004:3), I assume that stripping is simply gapping with one remnant.
} 
coordinate two vPs, the first containing sentence negation: ${ }^{35}$

\section{Step 1}

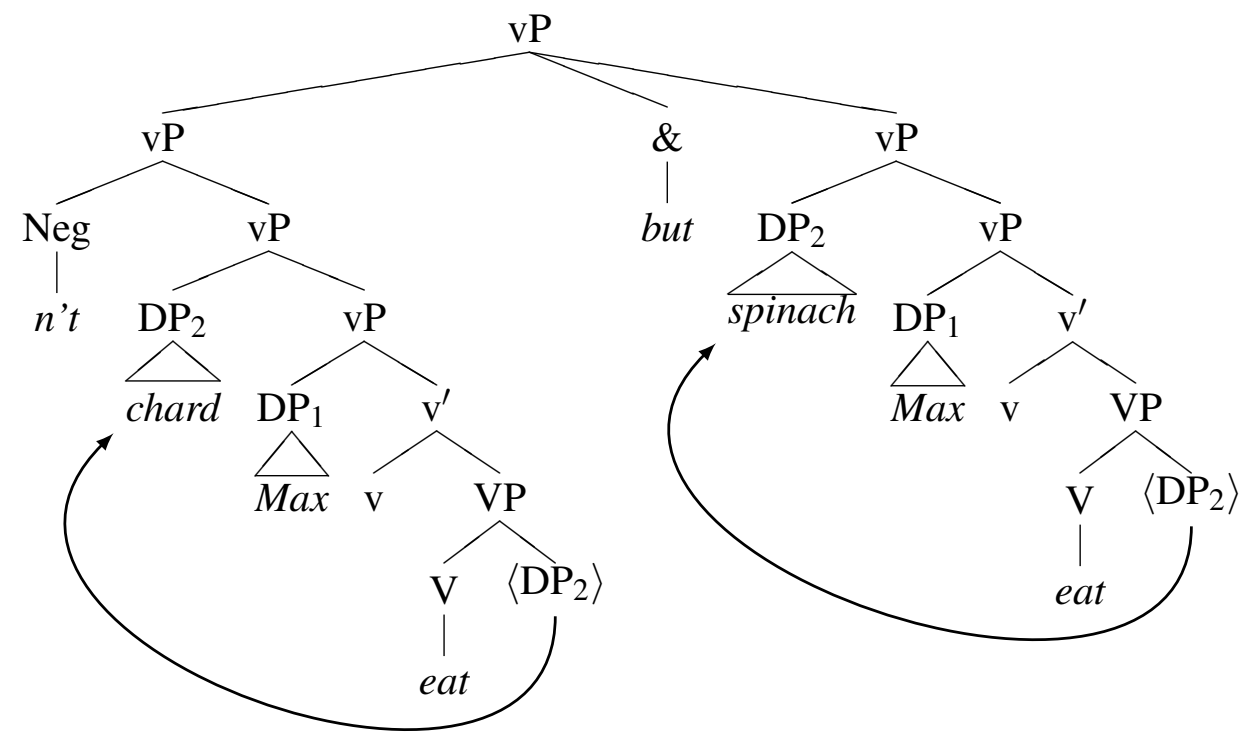

Sentence negation must be contained within the first coordinate, since semantically negation takes scope only inside the first conjunct.

The first step in the derivation raises the remnant and its correlate in the first coordinate to a vP-adjoined position. The final two steps in the derivation produce an ungrammatical string:

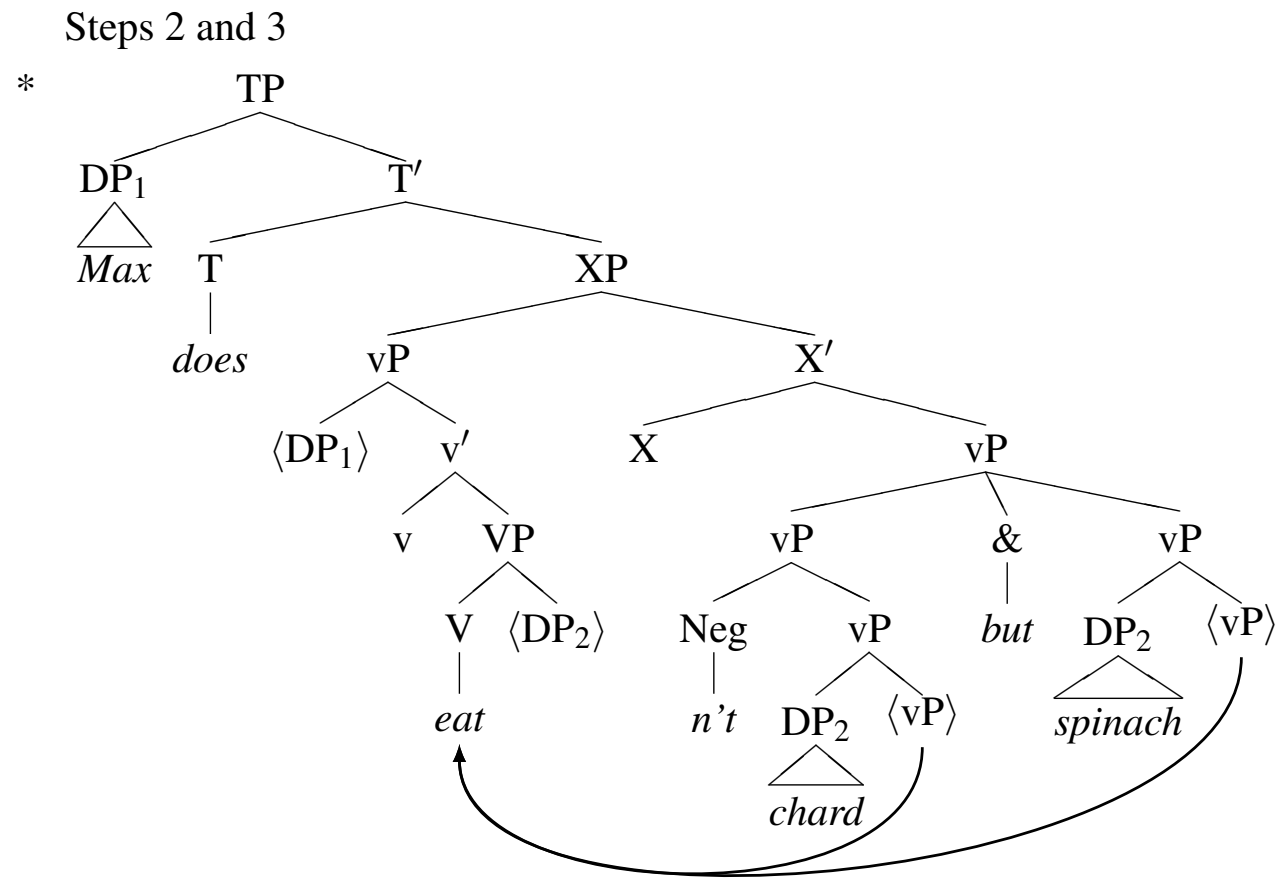

The vPs of each coordinate across-the-board move to SpecXP, after which the subject DP raises to SpecTP. This produces an illicit word order: the main verb eat precedes sentence negation.

\footnotetext{
${ }^{35}$ For simplicity, I assume that sentence negation is adjoined to the left edge of the vP. Of course, following Laka (1990:86-171), we might want to assume that sentence negation is one member of a more abstract category, Sectionigma. If so, then in (76) corrective but would coordinate two SectionigmaPs.
} 
Johnson's across-the-board movement treatment of gapping fails for corrective but, then, since its first coordinate always contains a negative element. Accordingly, across-the-board movement of vPs to a higher position can never produce the correct linear order for the main verb and negation.

\subsection{Ellipsis redux}

It is, in fact, somewhat difficult to tell how large the constituents are that corrective but combines in (76). If the Clause-Only Coordination Hypothesis does not hold, as I have argued, corrective but might, in fact, coordinate something smaller than full clauses, as in Johnson's across-the-board movement account. The small size of the coordination structure would be hard to see if ellipsis applied to the second coordinate, as in the proposals of Coppock (2001) and Lin (2002) for gapping.

Under this small coordination plus ellipsis approach to gapping, the sentence in (76) would have the parse in (90), where corrective but coordinates two vPs.

(90)

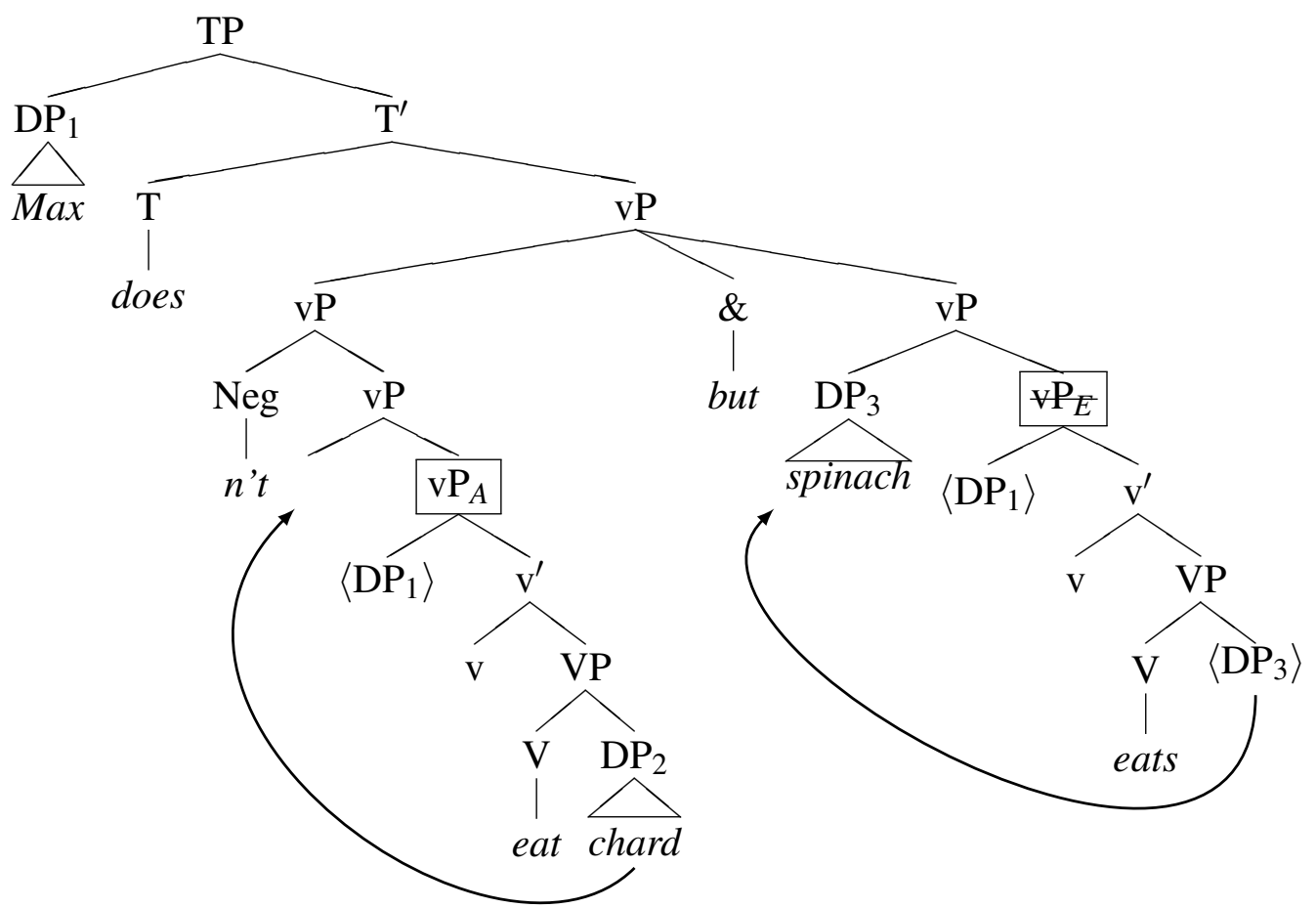

Just as with clausal ellipsis, the remnant in the second coordinate, $\mathrm{DP}_{3}$ spinach, must raise and adjoin outside the phrase that is elided. But in this small coordination structure, it is the vP of the second coordinate that goes missing under identity with the vP of the first coordinate.

In fact, there is independent evidence from quantifier binding that corrective but in (76) coordinates vPs. In (91a-b), a quantifier in subject position can take scope over corrective but, which takes sentence negation in its first coordinate.

(91) a. No child didn't eat chard but spinach.

'There was no child who did not eat chard and who ate spinach.' no $>\wedge$

b. At most five students didn't drink the whiskey but the gin.

'There were at most five students who did not drink the whiskey and who drank the gin.'

at most five $>\wedge$ 
(91a) is true in a state of affairs where there is no child who both did not eat chard and did eat spinach; and, (91b) is true in a state of affairs where at most five students both did not drink the whiskey and drank the gin. Another argument, provided by Johnson (2009:297f.), that corrective but does not coordinate full clauses in (76) comes from quantifiers in subject position, which can bind a variable in the remnant:

No woman didn't talk to an old friend, but her girlfriend.

'There is no woman such that she did not talk to an old friend and she talked to her girlfriend.'

No woman only c-commands the remnant her girlfriend if corrective but coordinates constituents smaller than full clauses (such as two vPs).

For the vP in the second coordinate of (90) to be elided, it must be identical to the antecedent $\mathrm{vP}$ in the first coordinate. As before, I assume that the correlate in the first coordinate, $\mathrm{DP}_{2}$ chard, can be factored out of the identity calculation by covert movement. ${ }^{36}$ The traces of the remnant and its correlate are $\exists$-bound, as are the traces of the external arguments of each vP, which have across-the-board moved to subject position:

$$
\begin{array}{rlrl}
\text { a. } & & \llbracket \mathrm{vP}_{A} \rrbracket & =\exists x \exists y(\operatorname{eat}(x)(y)) \\
\text { b. } & \llbracket \mathrm{vP}_{E} \rrbracket & =\exists x \exists y(\operatorname{eat}(x)(y))
\end{array}
$$

The elided and antecedent vPs entail each other, satisfying the identity constraint on ellipsis. Negation does not factor into this calculation, since it is located outside the antecedent vP. So, when the negative element in the first coordinate is sentence negation, corrective but must coordinate vPs for the identity constraint on ellipsis to be satisfied. This is only possible if the Clause-Only Coordination Hypothesis does not hold and corrective but is able to combine subclausal constituents. ${ }^{37}$

Finally, before moving on, I want to consider how the small coordination plus ellipsis account extends to the sentences in $(94 \mathrm{a}-\mathrm{j})$ with constituent negation, which a reviewer takes to be problematic. In each of these examples, constituent negation adjoins to a phrase that does not immediately precede corrective but; the coordinator appears in sentence-final position. To derive this surface order, corrective but must coordinate elements larger than are visible on the surface, with the second

\footnotetext{
${ }^{36}$ Coppock (2001:140) offers an alternate way of doing this that relies on the fact that the remnant and its correlate are both focused in gapping sentences. She invokes an addition clause in Merchant's (2001) definition of the eGIVENness identity constraint that allows not just traces to be $\exists$-bound but also expressions that are in focus. This gives the same result as covert movement of the correlate.

${ }^{37}$ A lingering mystery, originally identified by McCawley (1991:192), is why subject remnants are always impossible with corrective but:

(i) * Max doesn't eat chard, but Sam. Intended: 'Max does not eat chard; and, Sam eats chard.'

(ii) ?? Not Max eats chard, but Sam. Intended: 'Max does not eat chard; and, Sam eats chard.'

Regardless of whether the negative element is sentence negation, as in (i), or constituent negation, as in (ii), the remnant of ellipsis cannot be a subject. This restriction does not follow, in any way that I see, from either Vicente's treatment of corrective but or my own.
} 
coordinate being reduced to a remnant. But how, then, is the identity constraint on ellipsis satisfied when corrective but's first coordinate contains constituent negation ? $^{38}$

(94) a. He invited not Mary to the party, but Lucy.

b. He sent not just Mary to London, but the whole team.

c. He argued with not Mary about finances, but Lucy.

d. They revealed not the answers to the students, but the questions.

e. Someone left not a letter for us, but a postcard.

f. This pissed not Bill off, but Sue.

g. He gulped not one down, but five!

h. They detained not Bill for his indiscretions, but Mary.

i. They reengineered not the scissors for their flaw, but the paper handler.

j. They sent not the child to its room, but the older girl.

As with (76), corrective but in these examples could be coordinating vPs. ${ }^{39}$ The sentence in (94) would, for instance, have the structure in (95).

\footnotetext{
${ }^{38} \mathrm{~A}$ reviewer suggests a problem for an ellipsis account involving the possibility of sloppy interpretations for the possessive pronouns in $(94 \mathrm{~h}-\mathrm{j})$. The reviewer suggests that $(94 \mathrm{~h})$ only has a sloppy reading if Mary is construed as male, and that (94i) and (94j) lack sloppy readings altogether. I do not agree completely with these judgments. My intuition is that, in (94h) and (94j), sloppy interpretations for the possessive pronouns his and its are difficult, if not impossible, to get, since their binders, Mary and the older girl, do not agree in gender. But I have no problem with a sloppy interpretation for their, even though it does not agree in number with its binder, the paper handler. But as Kitagawa (1991:519-528) documents, there is significant dialectical variation regarding whether a sloppy interpretation is possible under ellipsis when there are mismatches in gender or number. Some speakers, including the reviewer and myself, do not allow a gender mismatch, while others do, giving rise to a sloppy interpretation. Consequently, we can conclude nothing from these facts about whether ellipsis applies in the derivation of $(94 \mathrm{a}-\mathrm{j})$.

${ }^{39}$ Given my assumptions about ellipsis, it would also be possible for corrective but to coordinate full clauses in $(94 \mathrm{a}-\mathrm{j})$. At present, I see no way of deciding between these analytical options. What is important, however, is that these examples do not pose a problem for the identity constraint on ellipsis.
} 
(95)

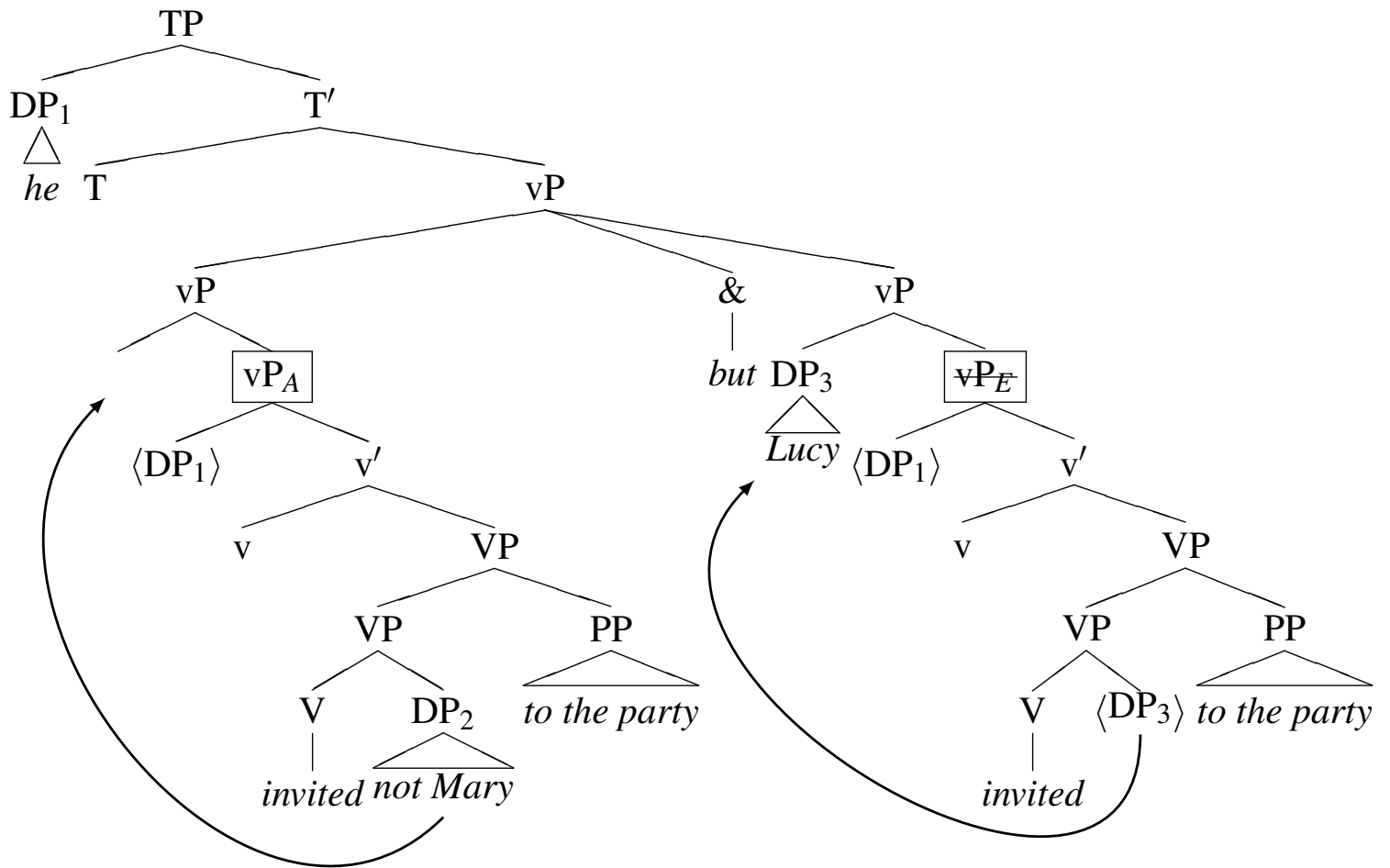

Corrective but coordinates two vPs. The remnant in the second coordinate, $\mathrm{DP}_{3} L u c y$, undergoes overt movement to adjoin outside the vP, while its correlate in the first coordinate, $\mathrm{DP}_{2}$ not Mary, raises covertly. At $\mathrm{LF}, \mathrm{vP}_{A}$ and $\mathrm{vP}_{E}$ consequently satisfy the identity constraint on ellipsis, since they mutually entail one another. The constituent negation in the first coordinate is, in particular, not a problem since it is adjoined to the correlate DP, which raises covertly out of the antecedent vP.

\section{Conclusion}

Vicente (2010) makes the novel argument that the syntax of corrective but is restricted - it is a coordinator that only coordinates full clauses. This conjecture, which I called the Clause-Only Coordination Hypothesis, is not correct. I identified sentences with corrective but that Vicente did not originally consider, in which corrective but does not coordinate full clauses. Instead, I proposed that corrective but has a crosscategorial syntax just like any other coordinator — that is, it is able to combine both clausal and subclausal constituents. This account provides intuitively satisfying analyses for a wide range of corrective but sentences. The analytical differences between my account and Vicente's account are summarized in Table 1 for a representative set of examples from the paper.

In closing, I would like to identify a couple of issues for the theory of ellipsis in coordination structures that this expanded typology of corrective but sentences raises. From Table 1, one might get the impression that there is some sort of dependency between the size of coordination and ellipsis. Looking at just the first two rows, it might seem that when corrective but coordinates small constituents ellipsis is never involved. Certainly no ellipsis is necessary to derive the surface form of the sentence in (10) since corrective but can coordinate DPs. There are, however, clearcut examples where corrective but coordinates small constituents and ellipsis does apply. In (96), 


\begin{tabular}{|c|c|c|}
\hline & VICENTE 2010 & PRESENT ACCOUNT \\
\hline \multicolumn{3}{|l|}{$\begin{array}{l}\text { 'basic form' } \\
{[\ldots \mathrm{V} \ldots[\mathrm{DP} \text { not ... but }[\mathrm{DP} \ldots]]}\end{array}$} \\
\hline (10) Max eats not spinach but chard. & $?$ & $\begin{array}{l}\text { DP coordination } \\
\text { with no ellipsis }\end{array}$ \\
\hline $\begin{array}{l}{[\ldots \mathrm{V} \ldots[\mathrm{DP} \text { Neg ... }] \text { but }[\mathrm{DP} \ldots]]} \\
\text { (46) } \ldots \text { he was no recluse but a man of the } \\
\text { world acquainted with public affairs. }\end{array}$ & $?$ & $\begin{array}{l}\text { DP coordination } \\
\text { with no ellipsis }\end{array}$ \\
\hline \multicolumn{3}{|l|}{$\begin{array}{l}\text { 'anchored form' } \\
{\left[\ldots n^{\prime} t \ldots \mathrm{V} \ldots[\mathrm{DP} \ldots] \ldots \text {... but }[\mathrm{DP} \ldots]\right]}\end{array}$} \\
\hline (9) Max doesn't eat spinach, but chard. & $\begin{array}{l}\text { CP coordination } \\
\text { with ellipsis }\end{array}$ & $\begin{array}{l}\text { vP coordination } \\
\text { with ellipsis }\end{array}$ \\
\hline 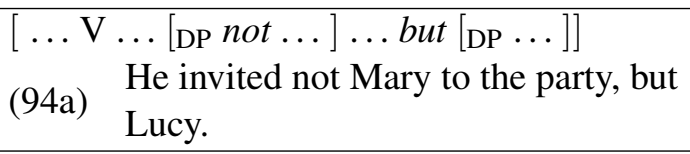 & $e_{1}$ & $\begin{array}{l}\text { vP coordination } \\
\text { with ellipsis }\end{array}$ \\
\hline $\begin{array}{l}{[[\text { DP } \text { not } \ldots] \text { C ... V ... but }[\text { DP ... }]]} \\
(55 b) \quad \text { Not Mary did he invite, but Lucy. }\end{array}$ & $\begin{array}{l}\text { CP coordination } \\
\text { with ellipsis }\end{array}$ & $\begin{array}{c}\mathrm{CP} \text { coordination } \\
\text { with ellipsis }\end{array}$ \\
\hline
\end{tabular}

Table 1: Representative corrective but sentences with their analysis under Vicente's account and the present account

for instance, corrective but coordinates two DPs with noun phrase ellipsis applying to reduce the second of them.

(96) Not all children, but some, will prefer the more reliable style of interaction they find in machines... ${ }^{40}$

Nonetheless, there does seem to be some sort of dependency between larger coordination structures with corrective but and ellipsis, which remains unexplained. Horn (2001:404) observes that it is ungrammatical for corrective but to coordinate full clauses without ellipsis applying to the second coordinate, as can be seen from the contrast in $(97 \mathrm{a}-\mathrm{b})$. He considers examples where the negative element is sentence negation, though the same point holds for when it is constituent negation, as in $(98 \mathrm{a}-\mathrm{b})$.

a. We don't have three children but four.

b. * We don't have three children but we have four.

(Horn 2001:404)

c. * We don't have three children but have four.

a. Max eats not chard but spinach.

b. * Max eats not chard but he eats spinach.

c. * Max eats not chard but eats spinach.

\footnotetext{
${ }^{40}$ Joanna J. Bryson. 2010. Why robot nannies probably won't do much psychological damage. Interaction Studies 11:196-200.
} 
The contrasts in (97a-b) and (98a-b) are surprising because ellipsis is not usually obligatory. Even if we take corrective but to be coordinating vPs in (97a), as I argued in Section 5.3, it does not seem possible for both vPs to be realized overtly without ellipsis, as in (97c) and (98c). ${ }^{41}$

This issue I suspect might be related to another open question involving ellipsis in coordinate structures. As Johnson (2009:293) discusses, the antecedent of gapping cannot — unlike the antecedents of other types of ellipsis - be contained inside an embedded clause:

* She said that Max brought gin to the party, and vodka (too).

Intended: 'She said that Max brought gin to the party, and he brought vodka to the party.'

(99) is ungrammatical when what has gone missing corresponds entirely to material contained in the embedded clause of the first coordinate. The remnant in corrective but sentences exhibits the same constraint:

(100) * She said that Max didn't bring gin to the party, but vodka.

Intended: 'She said that Max didn't bring gin to the party, and he brought vodka to the party.'

There is no corrective interpretation for (100), where it entails simply that she said that Max did not bring gin to the party and that Max brought vodka to the party. As Johnson rightly observes (p. 300f.), the account of gapping as small coordination and ellipsis proposed by Coppock (2001) and Lin (2002), which I extended to corrective but here, cannot account for this restriction on embedding the antecedent. So, there is more work that needs to be done to understand how ellipsis applies in coordinate structures. But I hope that the more complete picture of the syntax of corrective but that I have offered here - which dispenses with the Clause-Only Coordination Hypothesis — will bring us one step closer to this goal.

\section{Acknowledgements}

I thank Annahita Farudi, Kyle Johnson, Line Mikkelsen, Luis Vicente, and audiences at the Linguistic Society of America Annual Meetings in San Francisco and Pittsburgh and the Berkeley Syntax and Semantics Circle for their very helpful questions and suggestions. I am, in addition, extremely grateful to the editor and an anonymous reviewer for numerous probing comments, which improved greatly both the structure and content of the paper. This research was assisted by a New Faculty Fellowship from the American Council of Learned Societies, funded by the Andrew W. Mellon Foundation.

\section{References}

Abraham, Werner. 1979. But. Studia Linguistica 33:89-119.

Anscombre, Jean-Claude and Oswald Ducrot. 1977. Deux mais en français? Lingua 43:23-40.

\footnotetext{
${ }^{41} \mathrm{~A}$ number of speakers have remarked that they do not find (97b) particularly ungrammatical, in which case there would be no problem from this example for the ellipsis account. Nonetheless, as Marcel den Dikken points out, the parallel example with constituent negation in (98b) does seem significantly worse. There remains more to be explored here.
} 
Bach, Kent. 1999. The myth of conventional implicature. Linguistics and Philosophy 22:367-421. Beghelli, Filippo. 1994. Structured quantifiers. In Dynamics, polarity, and quantification, eds. Makoto Kanazawa and Christopher J. Piñón, 119-145. Stanford, CA: CSLI.

Bianchi, Valentina and Roberto Zamparelli. 2004. Edge coordinations: Focus and conjunction reduction. In Peripheries: Syntactic edges and their effects, eds. David Adger, Cécile de Cat, and George Tsoulas, 313-327. Dordrecht: Kluwer.

Bresnan, Joan W. 1974. The position of certain clause-particles in phrase structure. Linguistic Inquiry 5:614-619.

Chierchia, Gennaro and Sally McConnell-Ginet. 2000. Meaning and grammar: An introduction to semantics. Cambridge, MA: MIT Press, 2nd edition.

Chomsky, Noam. 1957. Syntactic structures. The Hague: Mouton.

Chung, Sandra, William A. Ladusaw and James McCloskey. 1995. Sluicing and logical form. Natural Language Semantics 3:239-282.

Coppock, Elizabeth. 2001. Gapping: In defense of deletion. Chicago Linguistic Society (CLS) 37:133-148.

Culicover, Peter and Ray Jackendoff. 2005. Simpler syntax. Oxford: Oxford University Press.

Dascal, Marcelo and Tamar Katriel. 1977. Between semantics and pragmatics: The two types of 'but'-Hebrew 'aval' and 'ela'. Theoretical Linguistics 4:143-172.

Gazdar, Gerald. 1980. A cross-categorial semantics for coordination. Linguistics and Philosophy 3:407-409.

Geurts, Bart. 1996. On no. Journal of Semantics 13:67-86.

Giannakidou, Anastasia. 1998. Polarity sensitivity as (non)veridical dependence. Amsterdam: John Benjamins.

Giannakidou, Anastasia and Melita Stavrou. 2009. On metalinguistic comparatives and negation in Greek. In Proceedings of the 2007 Workshop in Greek Syntax and Semantics at MIT, eds. Claire Halpert, Jeremy Hartman, and David Hill, volume 57 of MIT Working Papers in Linguistics, 5774. MITWPL.

Giannakidou, Anastasia and Suwon Yoon. 2011. The subjective mode of comparison: Metalinguistic comparatives in Greek and Korean. Natural Language and Linguistic Theory 29:621-655.

Grice, Herbert Paul. 1975. Logic and conversation. In Speech acts, eds. Peter Cole and Jerry L. Morgan, volume 3 of Syntax and Semantics, 41-58. New York: Academic Press.

Hankamer, Jorge. 1973. Unacceptable ambiguity. Linguistic Inquiry 4:17-68.

Hankamer, Jorge. 1979. Deletion in coordinate structures. New York: Garland Publishing.

Hartmann, Katharina. 2001. Right node raising and gapping: Interface conditions on prosodic deletion. Amsterdam: John Benjamins.

Horn, Laurence R. 2001. A natural history of negation. Stanford, CA: CSLI, 2nd edition.

Huddleston, Rodney and Geoffrey K. Pullum, eds. 2002. The Cambridge grammar of the English language. Cambridge: Cambridge University Press.

Iatridou, Sabine. 1990. About Agr(P). Linguistic Inquiry 21:551-577.

Jacobs, Joachim. 1980. Lexical decomposition in Montague Grammar. Theoretical Linguistics 7:121-136.

Johnson, Kyle. 2004. In search of the English middle field. Ms., University of Massachusetts, Amherst, URL http://people.umass.edu/kbj/homepage/Content/middle_field.pdf.

Johnson, Kyle. 2009. Gapping is not (VP-)ellipsis. Linguistic Inquiry 40:289-328. 
Kasimir, Elke. 2006. On 'nicht. . .sondern. ..' (contrastive 'not. ..but. ..'). In Interdisciplinary studies on information structure, eds. Shinichiro Ishihara, Michaela Schmitz, and Anne Schwarz, volume 5 of Working Papers of the SFB632, 107-151. Potsdam: Universitätsverlag Potsdam.

Keenan, Edward L. 1987. Multiply-headed Noun Phrases. Linguistic Inquiry 18:481-490.

Keenan, Edward L. and Leonard M. Faltz. 1985. Boolean semantics for natural language. Dordrecht: D. Reidel.

Keenan, Edward L. and Lawrence S. Moss. 1985. Generalized quantifies and the expressive power of natural language. In Generalized quantifiers in natural language, eds. Johan van Benthem and Alice ter Meulen, 73-124. Dordrecht: Foris.

Kim, Jong-Bok and Ivan A. Sag. 2002. Negation without head-movement. Natural Language and Linguistic Theory 20:339-412.

Kitagawa, Yoshihisa. 1991. Copying identity. Natural Language and Linguistic Theory 9:497-536.

Klima, Edward S. 1964. Negation in English. In The structure of language: Readings in the philosophy of language, eds. Jerry A. Fodor and Jerrold J. Katz, 246-323. Englewood Cliffs, NJ: Prentice-Hall, Inc.

Laka, Itziar. 1990. Negation in syntax: On the nature of functional categories and projections. Ph.D. Dissertation, Massachusetts Institute of Technology.

Lang, Edwald. 1984. The semantics of coordination. Amsterdam: John Benjamins.

Langacker, Ronald W. 1969. On pronominalization and the chain of command. In Modern studies in English: Readings in Transformational Grammar, eds. David A. Reibel and Sanford A. Schane, 160-186. New York: Prentice-Hall.

Lin, Vivian. 2002. Coordination and sharing at the interfaces. Ph.D. Dissertation, Massachusetts Institute of Technology.

McCawley, James D. 1991. Contrastive negation and metalinguistic negation. Chicago Linguistic Society (CLS) 27:189-206.

McCawley, James D. 1998. The syntactic phenomena of English. Chicago: University of Chicago Press, 2nd edition.

Merchant, Jason. 2001. The syntax of silence: Sluicing, islands, and the theory of ellipsis. Oxford: Oxford University Press.

Merchant, Jason. 2004. Fragments and ellipsis. Linguistics and Philosophy 27:661-738.

Merchant, Jason. 2008. Variable island repair under ellipsis. In Topics in ellipsis, ed. Kyle Johnson, 132-153. Cambridge: Cambridge University Press.

Moltmann, Friederike. 1992. Coordination and comparatives. Ph.D. Dissertation, Massachusetts Institute of Technology.

Morzycki, Marcin. 2011. Metalinguistic comparison in an alternative semantics for imprecision. Natural Language Semantics 19:39-86.

Munn, Alan B. 1993. Topics on the syntax and semantics of coordinate structures. Ph.D. Dissertation, University of Maryland.

Neijt, Anneke. 1979. Gapping: A contribution to sentence grammar. Dordrecht: Foris.

Oehrle, Richard T. 1987. Boolean properties in the analysis of gapping. In Discontinuous constituency, eds. Geoffrey J. Huck and Almerido E. Ojeda, volume 20 of Syntax and semantics, 201-240. San Diego, CA: Academic Press.

van Oirsouw, Robert R. 1987. The syntax of coordination. London: Croom Helm.

Partee, Barbara and Mats Rooth. 1983. Generalized conjunction and type ambiguity. In Meaning, 
use, and interpretation of language, eds. Rainer Bäuerle, Christoph Schwarze, and Arnim von Stechow, 361-383. Berlin: Walter de Gruyter.

Partee, Barbara H. 1986. Noun phrase interpretation and type-shifting principles. In Studies in Discourse Representation Theory and the theory of generalized quantifiers, eds. Jeroen Groenendijk, Dick de Jongh, and Martin Stokhof, 115-143. Dordrecht: Foris.

Potts, Christopher. 2000. When even no's Neg is Splitsville. In Jorge Hankamer WebFest, eds. Sandy Chung, Jim McCloskey, and Nathan Sanders. Department of Linguistics, University of California, Santa Cruz. URL http://babel.ucsc.edu/Jorge/potts.html.

Pusch, Luise. 1975. Über den Unterschied zwischen aber und sondern oder die Kunst des Widersprechens. In Syntaktische und semantische Studien zur Koordination, eds. Istán Bátori, Luise Pusch, and Jurij Levin, 45-62. Tübingen: Gunter Narr.

Repp, Sophie. 2009. Negation in gapping. Oxford: Oxford University Press.

Rizzi, Luigi. 1997. The fine structure of the left periphery. In Elements of grammar, ed. Liliane Haegeman, 281-337. Amsterdam: Kluwer.

Rooth, Mats and Barbara Partee. 1982. Conjunction, type ambiguity, and wide scope "or". In Proceedings of the First West Coast Conference on Formal Linguistics, eds. Daniel Flickenger, Marlys Macken, and Nancy Wiegand, 353-362. Stanford, CA: Linguistics Department, Stanford University.

Ross, John Robert. 1967. Constraints on variables in syntax. Ph.D. Dissertation, Massachusetts Institute of Technology.

Ross, John Robert. 1969. Guess who? Chicago Linguistic Society (CLS) 5:252-286.

Ross, John Robert. 1970. Gapping and the order of constituents. In Progress in linguistics, eds. Manfred Bierwisch and Karl Erich Heidolph, 249-259. The Hague: Mouton de Gruyter.

Rothstein, Susan. 1988. Conservativity and the syntax of determiners. Linguistics 26:999-1019. Sabbagh, Joseph. 2007. Ordering and linearizing rightward movement. Natural Language and Linguistic Theory 25:349-401.

Sag, Ivan A. 1976. Deletion and logical form. Ph.D. Dissertation, Massachusetts Institute of Technology.

Sag, Ivan A., Gerald Gazdar, Thomas Wasow and Steven Weisler. 1985. Coordination and how to distinguish categories. Natural Language and Linguistic Theory 3:117-171.

Schwenter, Scott A. 2000. Spanish connectives and pragmatic implicatures. In Hispanic linguistics at the turn of the millennium: Papers from the 3rd Hispanic Linguistics Symposium, eds. Héctor Campos, Elena Herburger, Alfonso Morales-Front, and Thomas J. Walsh, 292-307. Somerville, MA: Cascadilla Press.

Selkirk, Elisabeth. 2002. Contrastive FOCUS vs. presentational focus: Prosidic evidence from right node raising in English. In Speech prosody 2002: Proceedings of the 1st International Conference on Speech Prosody, 643-646. Aix-en-Provence: Laboratoire Parole et Langage, Université de Provence.

de Swart, Henriëtte. 2000. Scope ambiguities with negative determiners. In Reference and anaphoric relations, eds. Klaus von Heusinger and Urs Egli, 109-132. Amsterdam: Kluwer.

The British National Corpus, version 2. 2001. Distributed by Oxford University Computing Services on behalf of the BNC Consortium. URL http://www.natcorp.ox.ac.uk/.

Toosarvandani, Maziar. 2010. Association with foci. Ph.D. Dissertation, University of California, Berkeley. 
Toosarvandani, Maziar. To appear. Contrast and the structure of discourse. Semantics and Pragmatics URL http://ling.auf.net/lingbuzz/001567.

Vicente, Luis. 2010. On the syntax of adversative coordination. Natural Language and Linguistic Theory 28:381-415.

Wilder, Chris. 1994. Coordination, ATB, and ellipsis. Gröninger Arbeiten zur germanistischen Linguistik 37:291-392.

Wilder, Chris. 1997. Some properties of ellipsis in coordination. In Studies in Universal Grammar and typological variation, eds. Artemis Alexiadou and T. Alan Hall, 59-107. Amsterdam: John Benjamins.

Winter, Yoad. 2001. Flexibility principles in Boolean semantics: The interpretation of coordination, plurality, and scope in natural language. Cambridge, MA: MIT Press.

Massachusetts Institute of Technology

Department of Linguistics and Philosophy

32-D808

Cambridge, MA 02139

toosarva@mit.edu 